\title{
CrystEngComm
}

Check for updates

Cite this: CrystEngComm, 2018, 20, 755

Received 24th November 2017, Accepted 28th December 2017

DOI: 10.1039/c7ce02033c

rsc.li/crystengcomm

\section{Diversity of crystal structures and physicochemical properties of ciprofloxacin and norfloxacin salts with fumaric acid $\dagger$}

\author{
Artem O. Surov, (iD a Alexander P. Voronin, (iD ${ }^{a}$ Ksenia V. Drozd, (D) a \\ Andrei V. Churakov, ${ }^{b}$ Pascal Roussel iD c and German L. Perlovich iD*ad
}

\begin{abstract}
The crystallization of norfloxacin and ciprofloxacin - antibacterial fluoroquinolone compounds - with fumaric acid resulted in the isolation of six distinct solid forms of the drugs with different stoichiometries and hydration levels. Each salt can be selectively obtained by mechanochemical treatment in the presence of water/organic mixtures of a particular composition. The new phases were analysed using TG, DSC and PXRD, and their structural parameters were determined using single crystal X-ray diffraction. Despite having the same counterion, the ciprofloxacin and norfloxacin fumarates crystallise to form distinct crystal structures, which consequently determine the differences in the relative stability and the corresponding physicochemical properties of the solid forms. The influence of water activity $\left(a_{w}\right)$ on the solid form stability and transformation pathways of anhydrous and hydrated fumarates was elucidated. The solubility and phase stability of the salts were also investigated in pharmaceutically relevant buffer solutions with $\mathrm{pH} 6.8$ and $\mathrm{pH}$ 1.2. The largest solubility improvement relative to the parent drug ( $\approx 33$ times) in the $\mathrm{pH} 6.8$ medium was observed in the case of ciprofloxacin hemifumarate sesquihydrate. In turn, the norfloxacin fumarates showed a moderate 3 -fold enhancement in solubility.
\end{abstract}

\section{Introduction}

Norfloxacin (NFX) and ciprofloxacin (CIP) (Fig. 1) are potent fluoroquinolone antibacterial compounds, which are widely used in the treatment of various bacterial infections caused by both Gram-positive and Gram-negative bacteria. ${ }^{1,2}$ The aqueous solubility of fluoroquinolones is strongly $\mathrm{pH}^{-}$ dependent as proton transfer from the carboxylic acid to the basic piperazine ring leads to zwitterionic species formation. As a result, CIP and NFX have low solubility and poor permeability at neutral $\mathrm{pH}$ (BCS class IV) limiting the bioavailability

\footnotetext{
${ }^{a}$ Institution of the Russian Academy of Sciences, G.A. Krestov Institute of Solution Chemistry RAS, 153045, Ivanovo, Russia. E-mail: glp@isc-ras.ru; Fax: (+7) 4932 336237; Tel: (+7) 4932533784

${ }^{b}$ Institute of General and Inorganic Chemistry RAS, 31 Leninsky Prosp, 119991 Moscow, Russia

${ }^{c}$ UCCS UMR 8181 University des Sciences et Technologies de Lille-1, Lille, France ${ }^{d}$ Department of Chemistry, Lomonosov Moscow State University, Moscow, Russia $\dagger$ Electronic supplementary information (ESI) available: Results of mechanochemical search for crystal forms (Tables S1 and S2), TG and DSC analysis (Fig. S1, S2, S4, S5 and S12) experimental and calculated PXRD patterns (Fig. S3 and S6-S8), illustration of molecular packing arrangements of the [NFX + Succinic + $\mathbf{H}_{2} \mathrm{O}$ ] $(1: 0.5: 1)$ (Fig. S9), [CIP + Fum $\left.+\mathbf{H}_{2} \mathrm{O}\right](1: 1: 0.16)$ (Fig. S10) and [CIP + Fum $+\mathrm{H}_{2} \mathrm{O}$ ] (1: $\left.0.5: 1.5\right)$ salts (Fig. S11), results of PXRD analysis of residual materials after stability studies (Fig. S13) and dissolution of the salts (Fig. S14-S16), intrinsic dissolution rates of the fluoroquinolones and their salts with fumaric acid in pH 1.2 media (Table S3). CCDC 1567143-1567145, 1567678. For ESI and crystallographic data in CIF or other electronic format see DOI: 10.1039/c7ce02033c
}

of the compounds. ${ }^{3,4}$ These drawbacks lead to significant challenges in the formulation of conventional dosage forms, e.g. tablets, and obstruct the design of liquid dosage forms, such as parenteral and ophthalmic solutions. One of the common procedures to improve the aqueous solubility of a drug is salt formation using a suitable counterion. It was recently demonstrated that the solubility of pure CIP is determined by solid-state issues, since the zwitterionic molecules in their crystal form are held together by strong dipole-dipole interactions. ${ }^{5}$ Salt formation changes the state of CIP molecules in their crystal form from zwitterionic to cationic, effectively reducing the lattice energy and improving aqueous solubility. ${ }^{6}$ Therefore, a number of efforts have been made to extend the range of fluoroquinolone solid forms and to modify the poor solubility performance of CIP and NFX through salt preparation with different organic acids, including aliphatic ${ }^{7-12}$ and aromatic carboxylic acids, ${ }^{13-16}$ derivatives of sulfonic acids, ${ }^{14}$

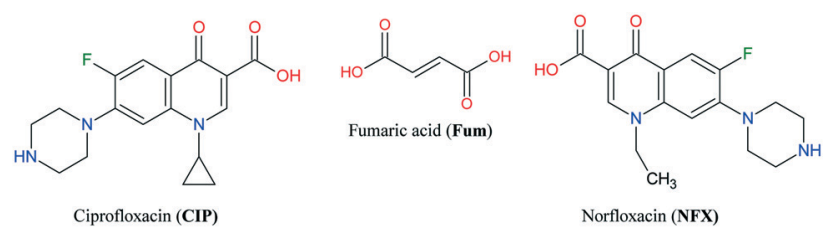

Fig. 1 Molecular structures of ciprofloxacin (CIP), norfloxacin (NFX) and fumaric acid. 
and artificial sugars. ${ }^{17-20}$ Recently, a new drug-drug multicomponent solid consisting of two antibacterial agents, namely norfloxacin and sulfathiazole, has been obtained. ${ }^{21}$ However, according to the Orange Book list ${ }^{22}$ only a few of the reported solid forms contain FDA-approved counterions (such as citrate, maleate, fumarate, succinate, etc. ${ }^{23}$ ) and, therefore, may be considered pharmaceutically relevant. Organic counterions have gained increased attention in pharmaceutical salts formulation in the last decade ${ }^{24}$ since they are less likely to disproportionate in aqueous solutions due to a lower $\mathrm{p} K_{\mathrm{a}}$ difference ${ }^{25}$ and may also show better solubility performance in gastric media compared to hydrochloride due to the common ion effect of the latter. With regard to this, possible crystal forms of fluoroquinolones with organic acids may become a viable alternative to commercially available hydrochloride salts.

The literature survey suggests that the fluoroquinolones tend to form salts with multiple stoichiometries and variable water content. For example, Velaga et al. reported a conventional salt and a salt-cocrystal of norfloxacin with saccharin. ${ }^{18}$ Paluch et al. were able to isolate six distinct solid forms of ciprofloxacin succinate, including four crystalline forms with various drug/acid stoichiometries and hydration levels, and two amorphous forms. ${ }^{9}$ The fact that several alternative solid forms coexist at the same temperature and pressure implies proximity in their Gibbs free energies. In the case of hydrates, water molecules make an important contribution to stabilizing the crystal lattice of a solid, ${ }^{26}$ filling the excess of the free volume (decreasing entropy) and connecting the constituents of the multi-component crystal via intermolecular interactions (increasing enthalpy). It is evident that any changes in the crystal structure of the solid form inevitably alter its physicochemical properties, including solubility and dissolution rate. Like polymorphic forms, salts with multiple drug/acid stoichiometries and/or water contents differ in their thermodynamic and physical stability and hence may undergo various solid state phase transformations (e.g. hydrate formation) depending on temperature, relative humidity, dissolution medium, etc. The effect of such transformations on the solubility performance of a salt is hard to predict. Therefore, it is important to take into account the tradeoff between the physicochemical properties of a particular solid form and its thermodynamic stability.

In this research, we report crystal structures, physicochemical properties, thermodynamic stability and solubility of the fumarate salts of ciprofloxacin and norfloxacin with different stoichiometry values and hydration levels. Although ciprofloxacin fumarate monohydrate $(1: 1: 1)$ and ciprofloxacin hemifumarate sesquihydrate $(1: 0.5: 1.5)$ have been described earlier, ${ }^{10,12}$ norfloxacin salts with fumaric acid are reported for the first time. It has been found that each fluoroquinolone can form three distinct salt forms with fumaric acid, namely two forms with a 1:1 drug/acid stoichiometry and one form with a 1:0.5 drug/acid stoichiometry. A broad range of analytical techniques was applied to characterise the fumarate salts, including X-ray diffraction (powder and single crystal), differential scanning calorimetry (DSC), thermogravimetric analysis (TGA), water activity measurements (slurry method), dissolution and solubility investigation at the physiological $\mathrm{pH}$ values (1.2 and 6.8). It is known that experimental form screening is routinely conducted in the pharmaceutical industry to ensure that all the forms have been found and that the most appropriate solid form is developed. ${ }^{27}$ Therefore, the present work seeks to establish the influence of crystal structure and hydration level of the ciprofloxacin and norfloxacin fumarates on their stability and solubility with the aim of selecting the salt form with the optimal characteristics for further development.

\section{Materials and methods}

\subsection{Compounds and solvents}

Ciprofloxacin $\left(\mathrm{C}_{17} \mathrm{H}_{18} \mathrm{FN}_{3} \mathrm{O}_{3}\right.$, anhydrous, 98\%), norfloxacin $\left(\mathrm{C}_{16} \mathrm{H}_{18} \mathrm{FN}_{3} \mathrm{O}_{3}\right.$, anhydrous, $\left.98 \%\right)$ and fumaric acid $\left(\mathrm{C}_{4} \mathrm{H}_{4} \mathrm{O}_{4}\right.$, 99\%) were purchased from Acros Organics. All solvents were available commercially and used as received without further purification.

\subsection{Grinding experiments}

Grinding experiments were performed using a Fritsch planetary micro mill, model Pulverisette 7 , in $12 \mathrm{ml}$ agate grinding jars with ten $5 \mathrm{~mm}$ agate balls at a rate of $500 \mathrm{rpm}$ for 40 min. In a typical experiment, $80 \mathrm{mg}$ of a fluoroquinolone and fumaric acid mixture in a $1: 1$ or $2: 1$ molar ratio was placed into a grinding jar, and $60 \mu \mathrm{l}$ of solvent was added using a micropipette. In the case of phase stability studies, $80 \mathrm{mg}$ of the solid form and $60 \mu \mathrm{l}$ of the solvent were ground for 40 min at $500 \mathrm{rpm}$.

\subsection{Solution crystallization}

Ciprofloxacin fumarate ([Cip + Fum] (1:1)). The powder sample of the salt obtained by mechanochemical treatment was placed into hot methanol $\left(40-50{ }^{\circ} \mathrm{C}\right)$ and stirred until a clear solution was obtained. The solution was slowly cooled and kept in a fume hood at room temperature until a crystalline material was formed.

Norfloxacin fumarate monohydrate ([NFX + Fum $\left.+\mathrm{H}_{2} \mathrm{O}\right]$ $(1: 1: 1)$ ). Good quality single crystals of the salt were obtained by seeding the hot methanol-water solution $(80: 20$ $\mathrm{v}: \mathrm{v}$ ) of the components in a 1:1 molar ratio with the ground powder of norfloxacin fumarate monohydrate.

Norfloxacin fumarate dihydrate $\left(\left[\mathrm{NFX}+\right.\right.$ Fum $\left.+\mathrm{H}_{2} \mathrm{O}\right](1: 1$ : 2)). Crystallization of norfloxacin fumarate dihydrate can be achieved by slow cooling of methanol-water, ethanol-water or acetonitrile-water solutions (50:50 v:v) containing an equimolar mixture of the components.

Norfloxacin hemifumarate monohydrate ([NFX + Fum + $\left.\left.\mathrm{H}_{2} \mathrm{O}\right] \quad(1: 0.5: 1)\right)$. The single crystals of norfloxacin hemifumarate monohydrate were obtained from a gently cooled methanol-water solution $(75: 25 \mathrm{v}: \mathrm{v})$ containing an equimolar mixture of the components. 
Norfloxacin hemisuccinate monohydrate ([NFX + succinic $\left.\left.+\mathrm{H}_{2} \mathrm{O}\right](1: 0.5: 1)\right)$. Norfloxacin hemisuccinate monohydrate $\left(\left[\mathrm{NFX}+\right.\right.$ succinic $\left.\left.+\mathrm{H}_{2} \mathrm{O}\right](1: 0.5: 1)\right)$ was prepared according to the procedure described by Basavoju et $a l^{7}$

\subsection{X-ray diffraction experiments}

Single-crystal X-ray diffraction data were collected on a Bruker SMART APEX II diffractometer using graphitemonochromated MoK $\alpha$ radiation $(\lambda=0.71073 \AA$ ). Absorption corrections based on measurements of equivalent reflections were applied. $^{28}$ The structures were solved by direct methods and refined by full matrix least-squares on $F^{2}$ with anisotropic thermal parameters for all non-hydrogen atoms. ${ }^{29}$ In the structure [Cip + Fum] the solvent water positions with low occupancy $(0.115)$ were observed. In $\left[\mathrm{NFX}+\right.$ Fum $\left.+\mathbf{H}_{2} \mathbf{O}\right]$ (1: $0.5: 1)$ all hydrogen atoms were found from the difference Fourier map and refined isotropically. As for [Cip + Fum], all $\mathrm{H}$ atoms (except for partially occupied solvent $\mathrm{H}_{2} \mathrm{O}$ ) were also found from the difference Fourier map and their positional and thermal parameters were refined. Water $\mathrm{H}$ atom positions were calculated (on the $011 \cdots{ }^{-} \mathrm{O}_{2} \mathrm{C}$ lines at the distances $0.8 \AA$ from water oxygen) and refined using a riding model. In $\left[\mathbf{N F X}+\mathbf{F u m}+\mathbf{H}_{2} \mathbf{O}\right](1: 1: 2)$ all "active" (amino and hydroxy) hydrogen atoms were found from the difference Fourier map and refined isotropically. All other $\mathrm{H}$ atoms (carbon) were placed in calculated positions and refined using a riding model. The crystallographic data for anhydrous ciprofloxacin hemifumarate, monohydrate and dihydrate of norfloxacin hemifumarate have been deposited with the Cambridge Crystallographic Data Centre as supplementary publications under the CCDC numbers 1567143-1567145. Single-crystal X-ray diffraction data for $\left[\mathbf{N F X}+\mathbf{F u m}+\mathbf{H}_{2} \mathbf{O}\right]$ (1:1:1) were collected on a Bruker AXS Kappa APEX II diffractometer at $100 \mathrm{~K}$. The structure was solved and refined using Olex2 software ${ }^{30}$ and deposited under the CCDC number 1567678 .

$\mathrm{X}$-ray powder diffraction (PXRD) data of the bulk materials were recorded under ambient conditions in a Bragg-Brentano geometry with a Bruker D8 Advance diffractometer with $\operatorname{CuK} \alpha_{1}$ radiation $(\lambda=1.5406 \AA)$.

\subsection{DSC experiments}

Thermal analysis was carried out using a Perkin Elmer DSC 4000 differential scanning calorimeter with a refrigerated cooling system (USA). The sample was heated in sealed aluminum sample holders with a pierced lid at a rate of $10{ }^{\circ} \mathrm{C}$ $\min ^{-1}$ in a nitrogen atmosphere. The unit was calibrated with indium and zinc standards. The accuracy of the weighing procedure was $\pm 0.01 \mathrm{mg}$.

\subsection{Thermogravimetric analysis (TGA)}

TGA was performed on a TG 209 F1 Iris thermomicrobalance (Netzsch, Germany). Approximately $10 \mathrm{mg}$ of the sample was added to a platinum crucible. The samples were heated at a constant heating rate of $10{ }^{\circ} \mathrm{C} \mathrm{min}^{-1}$. The samples were purged with a stream of flowing dry Ar at $30 \mathrm{ml} \mathrm{min}{ }^{-1}$ throughout the experiment.

\subsection{Aqueous solubility experiments}

Kinetic and thermodynamic solubility measurements were carried out by the shake-flask method in a phosphate buffer with pH 6.8 and a hydrochloric buffer with $\mathrm{pH} 1.2$ at $25.0 \pm$ $0.1{ }^{\circ} \mathrm{C}$. All kinetic solubility experiments were performed under non-sink conditions. In a typical experiment, the excess amount of each sample was suspended in $10 \mathrm{ml}$ of the buffer solution preheated to $25.0{ }^{\circ} \mathrm{C}$ in Pyrex glass tubes. The tubes were further placed into an air thermostat supplied by an end-over-end shaker device and shaken at a constant speed. Aliquots of the suspension were withdrawn at predetermined intervals and filtered through a $0.22 \mu \mathrm{m}$ PTFE syringe filter (Rotilabo®), and the content of the drug in the solution phase was determined with suitable dilution using a Cary 50 UV-vis spectrophotometer (Varian, Australia) at the reference wavelength. For the solubility measurements, the excess amount of the solid form was suspended in $2 \mathrm{ml}$ of the solvent and allowed to equilibrate under shaking at $25.0^{\circ} \mathrm{C}$ for 48 hours. The results are stated as the average of at least four replicated experiments. The stability of the salts in the solubility experiments was monitored by analyzing samples from the bottom phase after 6, 24 and 48 hours using PXRD.

\subsection{Intrinsic dissolution rate}

Intrinsic dissolution rate (IDR) measurements were carried out on a USP-certified Electrolab EDT-08LX dissolution tester by the disk intrinsic dissolution method. For the IDR experiments, approximately $200 \mathrm{mg}$ of pure drug or salt was compressed by a hydraulic press for $5 \mathrm{~min}$ to form a nonporous compact $8 \mathrm{~mm}$ in diameter. The intrinsic attachment with the sample was rotated at $150 \mathrm{rpm}$ in $500 \mathrm{ml}$ of the buffer media with $\mathrm{pH} 1.2$ preheated to $37.0{ }^{\circ} \mathrm{C}$. The cumulative amount dissolved per unit surface area was determined by taking aliquots of $2 \mathrm{ml}$ at specific time intervals, with volume replacement and the concentration measured spectrophotometrically. The slope of the plot of the mass dissolved per unit surface area $v s$. time represents the intrinsic dissolution

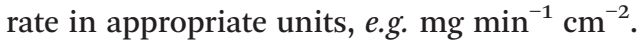

\subsection{Evaluation of phase stability at different water activities}

The influence of water activity on the stability of the hydrated/ dehydrated forms of the salts was studied using a series of methanol/water binary mixtures with varying water content. The water activity of the binary mixtures was calculated from the following polynomial equation proposed by Zhu et al.: ${ }^{31}$

$a_{\mathrm{w}}=0.0056+1.398 \cdot x_{\mathrm{w}}-0.647 \cdot x_{\mathrm{w}}{ }^{2}+0.153 \cdot x_{\mathrm{w}}{ }^{3}+0.0845 \cdot x_{\mathrm{w}}{ }^{4}(1)$

where $a_{\mathrm{w}}$ is the water activity and $x_{\mathrm{w}}$ is the mole fraction of water.

In a typical experiment, $30 \mathrm{mg}$ of [Cip + Fum] (1:1) or $\left[\mathrm{NFX}+\right.$ Fum $\left.+\mathrm{H}_{2} \mathrm{O}\right](1: 1: 1)$ was suspended in $1.6 \mathrm{ml}$ of a 
water-methanol mixture in a sealed vial and left to shake at $25{ }^{\circ} \mathrm{C}$ for at least 4 days. Where stated, the initial suspension was seeded with an alternative phase to initiate phase transition. After equilibration, the suspension was centrifuged, the clear solution was filtered through a $0.22 \mu \mathrm{m}$ PTFE filter and the concentration of fluoroquinolone was measured by absorbance spectroscopy after necessary dilution using a Cary 50 UV-vis spectrophotometer (Varian) at the reference wavelength. In each experiment, the precipitate was collected, dried carefully at room temperature and identified by PXRD.

\section{Results and discussion}

\subsection{Crystal structures of ciprofloxacin and norfloxacin fumarates}

The crystal structures of $\left[\mathbf{C I P}+\mathbf{F u m}+\mathbf{H}_{2} \mathbf{O}\right](1: 1: 1)$ and [CIP + Fum $\left.+\mathrm{H}_{2} \mathrm{O}\right](1: 0.5: 1.5)$ have been described in previous works. $^{10,12}$ The relevant crystallographic data for the previously unknown hydrates of norfloxacin fumarate and the anhydrous ciprofloxacin fumarate salts are given in Table 1. The asymmetric unit of $\left[\mathbf{N F X}+\mathbf{F u m}+\mathbf{H}_{2} \mathbf{O}\right](1: 1: 1)$ contains a norfloxacin cation, a fumarate anion and one water molecule. There are two $\mathrm{N}^{+}-\mathrm{H}^{\cdots} \mathrm{O}^{-}$and $\mathrm{N}^{+}-\mathrm{H}^{\cdots} \mathrm{O}$ hydrogen bonds that connect each protonated NFX ion with one fumarate ion and one water molecule, respectively. In turn, the fumarate anions are linked to each other via charge-assisted $\mathrm{O}-\mathrm{H}^{\cdots} \mathrm{O}^{-}$ hydrogen bonds to form $\mathrm{C}(7)$ hydrogen bonded chains ${ }^{32,33}$ along the $b$-axis (Fig. 2a). The neighbouring chains are further connected through the water molecules, and the latter are responsible for the formation of the ring $R_{6}^{4}(16)$ motifs (Fig. 2a). It would be interesting to compare the packing ar-

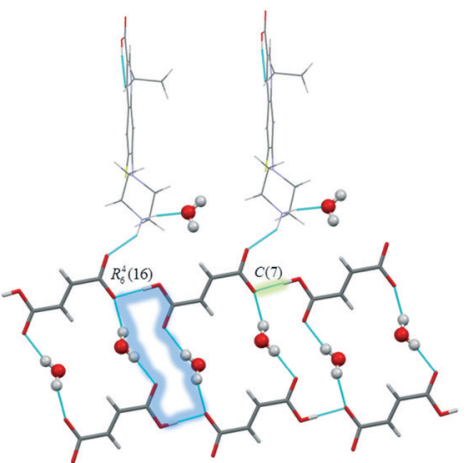

(a)

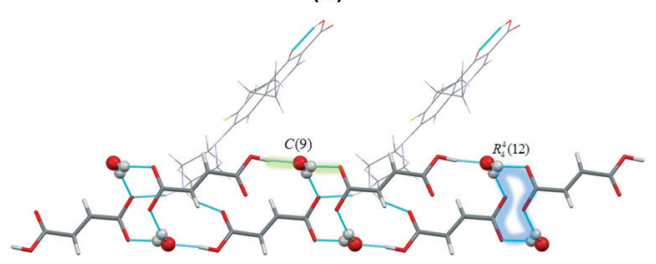

(b)

Fig. 2 Illustration of hydrogen bond patterns in the crystals of (a) [NFX + Fum + $\left.\mathrm{H}_{2} \mathrm{O}\right](1: 1: 1)$ and (b) [CIP + Fum + $\left.\mathrm{H}_{2} \mathrm{O}\right](1: 1: 1)$.

rangements and hydrogen bond patterns in two fumarate monohydrates of norfloxacin and ciprofloxacin ([NFX + Fum $\left.+\mathrm{H}_{2} \mathrm{O}\right](1: 1: 1)$ and $\left.\left[\mathrm{CIP}+\mathbf{F u m}+\mathbf{H}_{2} \mathrm{O}\right](1: 1: 1)\right)$. In the crystal of $\left[\mathbf{C I P}+\right.$ Fum $\left.+\mathbf{H}_{2} \mathbf{O}\right](1: 1: 1)$, water molecules are not seen to be involved in hydrogen bonding with CIP ions. Instead, $\mathrm{H}_{2} \mathrm{O}$ molecules play an important structure-forming role acting as bridges between the fumarate anions to form a rigid

Table 1 Crystallographic data for norfloxacin fumarate hydrates and ciprofloxacin fumarate salt

\begin{tabular}{|c|c|c|c|c|}
\hline Compound reference & $\begin{array}{l}{\left[\mathrm{NFX}+\mathrm{Fum}+\mathrm{H}_{2} \mathrm{O}\right]} \\
(1: 1: 1)\end{array}$ & $\begin{array}{l}{\left[\mathrm{NFX}+\mathrm{Fum}+\mathrm{H}_{2} \mathrm{O}\right]} \\
(1: 1: 2)\end{array}$ & $\begin{array}{l}{\left[\mathrm{NFX}+\text { Fum }+\mathrm{H}_{2} \mathrm{O}\right]} \\
(1: 0.5: 1)\end{array}$ & {$[\mathrm{CIP}+\mathrm{Fum}](1: 1)$} \\
\hline Chemical formula & $\begin{array}{l}\mathrm{C}_{16} \mathrm{H}_{19} \mathrm{FN}_{3} \mathrm{O}_{3} \cdot \mathrm{C}_{4} \mathrm{H}_{3} \mathrm{O}_{4} \\
\cdot 1\left(\mathrm{H}_{2} \mathrm{O}\right)\end{array}$ & $\begin{array}{l}\mathrm{C}_{16} \mathrm{H}_{19} \mathrm{FN}_{3} \mathrm{O}_{3} \cdot \mathrm{C}_{4} \mathrm{H}_{3} \mathrm{O}_{4} \\
\cdot 2\left(\mathrm{H}_{2} \mathrm{O}\right)\end{array}$ & $\begin{array}{l}\mathrm{C}_{16} \mathrm{H}_{19} \mathrm{FN}_{3} \mathrm{O}_{3} \cdot 0.5\left(\mathrm{C}_{4} \mathrm{H}_{2} \mathrm{O}_{4}\right) \\
\cdot 1\left(\mathrm{H}_{2} \mathrm{O}\right)\end{array}$ & $\begin{array}{l}\mathrm{C}_{17} \mathrm{H}_{19} \mathrm{FN}_{3} \mathrm{O}_{3} \cdot \mathrm{C}_{4} \mathrm{H}_{3} \mathrm{O}_{4} \\
\cdot 0.155\left(\mathrm{H}_{2} \mathrm{O}\right)\end{array}$ \\
\hline Fw & 453.42 & 471.44 & 790.77 & 450.21 \\
\hline Crystal system & Monoclinic & Monoclinic & Triclinic & Monoclinic \\
\hline Space group & $P 2_{1} / c$ & $P 2_{1} / n$ & $P \overline{1}$ & $P 2_{1} / c$ \\
\hline$a / \AA ̊$ & $16.6277(4)$ & $8.1127(8)$ & $6.7869(4)$ & $8.0133(9)$ \\
\hline$b / \AA$ & $7.3695(2)$ & $9.6281(9)$ & $9.3544(6)$ & $37.244(4)$ \\
\hline$c / \AA$ & $17.1695(5)$ & $27.380(3)$ & $15.7300(9)$ & $6.9698(8)$ \\
\hline$\alpha /^{\circ}$ & 90 & 90 & $93.6351(9)$ & 90 \\
\hline$\beta / \circ$ & $100.1910(10)$ & $93.525(2)$ & $92.6297(9)$ & $92.806(2)$ \\
\hline$\gamma /{ }^{\circ}$ & 90 & 90 & $110.9168(9)$ & 90 \\
\hline Unit cell volume $/ \AA^{3}$ & $2070.72(10)$ & $2134.6(4)$ & $928.45(10)$ & $2077.6(4)$ \\
\hline $\begin{array}{l}\text { No. of formula units per unit } \\
\text { cell, } Z\end{array}$ & 4 & 4 & 1 & 4 \\
\hline Temperature/K & 100 & 150 & 150 & 150 \\
\hline Absorption coefficient, $\mu / \mathrm{mm}^{-1}$ & 0.119 & 0.122 & 0.113 & 0.115 \\
\hline No. of reflections measured & 41493 & 17344 & 10525 & 22847 \\
\hline No. of independent reflections & 4578 & 3782 & 4924 & 5508 \\
\hline$R_{\text {int }}$ & 0.032 & 0.0546 & 0.0141 & 0.0305 \\
\hline Final $R_{1}$ values $(I>2 \sigma(I))$ & 0.0367 & 0.0392 & 0.0359 & 0.0427 \\
\hline Final $w R\left(F^{2}\right)$ values $(I>2 \sigma(I))$ & 0.0943 & 0.0810 & 0.0985 & 0.1072 \\
\hline Final $R_{1}$ values (all data) & 0.0442 & 0.0613 & 0.0418 & 0.0545 \\
\hline Final $w R\left(F^{2}\right)$ values (all data) & 0.0989 & 0.0898 & 0.1034 & 0.1150 \\
\hline Goodness of fit on $F^{2}$ & 1.028 & 1.021 & 1.040 & 1.025 \\
\hline Largest diff. peak \& hole, e $\AA^{-3}$ & $0.340 /-0.210$ & $0.177 /-0.194$ & $0.381 /-0.235$ & $0.432 /-0.233$ \\
\hline
\end{tabular}


three-dimensional layer via the $\mathrm{C}(9)$ hydrogen bonded chains and $\mathrm{R}_{4}^{4}(12)$ ring motifs (Fig. $\left.2 \mathrm{~b}\right)$. In [NFX + Fum $\left.+\mathbf{H}_{2} \mathbf{O}\right](1: 1$ : 1), however, water molecules mainly serve as connectors of neighbouring chains of the fumarate ions with each other and with the NFX ions. At the macroscopic level, these differences in water accommodation make a considerable impact on the thermal stability of the corresponding hydrates (this aspect is discussed below). Similar to monohydrate of norfloxacin fumarate, in the crystal of $\left[\mathrm{NFX}+\right.$ Fum $\left.+\mathbf{H}_{2} \mathrm{O}\right](1: 1$ : 2 ), the fumarate ions are assembled into infinite chains with the $\mathrm{C}(7)$ graph set notation, so that each counterion in a chain is linked with an NFX cation through one chargeassisted $\mathrm{N}^{+}-\mathrm{H}^{\cdots} \mathrm{O}^{-}$hydrogen bond (Fig. 3). In this case, however, $\mathrm{H}_{2} \mathrm{O}$ molecules do not participate in connecting the neighbouring chains of fumarate ions as seen in [CIP + Fum $\left.+\mathbf{H}_{2} \mathrm{O}\right](1: 1: 1)$ and $\left[\mathrm{NFX}+\mathrm{Fum}+\mathbf{H}_{2} \mathrm{O}\right](1: 1: 1)$. Of the five distinct hydrogen bonds per two water molecules in the crystal of dihydrate, only one is engaged by the counterion. Another $\mathrm{H}$-bond connects $\mathrm{H}_{2} \mathrm{O}$ molecules with each other. The rest of the three hydrogen bonds are formed with the participation of the carboxylic group and the piperazinyl moiety of norfloxacin (Fig. 3). The packing arrangement of the $[\mathbf{N F X}+$ Fum $\left.+\mathrm{H}_{2} \mathrm{O}\right](1: 1: 1)$ salt is found to be typical of fluoroquinolone multi-component crystals.

$\left[\mathrm{NFX}+\right.$ Fum $\left.+\mathrm{H}_{2} \mathrm{O}\right](1: 1: 1)$ consists of conventional layers of columnar $\pi$-stacks of the drug separated by domains containing fumarate ions and water molecules (Fig. 4b). In the $\left[\mathbf{N F X}+\mathbf{F u m}+\mathbf{H}_{2} \mathbf{O}\right](1: 1: 2)$ structure, the layers are less prominent (Fig. 4a). The $\mathrm{H}$-bonded chains of fumarate ions are located inside the voids formed by NFX, whereas $\mathrm{H}_{2} \mathrm{O}$ molecules reside in the hydrophilic surroundings of carboxylic and piperazinyl. In the $\left[\mathrm{NFX}+\right.$ Fum $\left.+\mathrm{H}_{2} \mathrm{O}\right](1: 0.5: 1)$ crystal, the fully deprotonated anion of fumaric acid accepts charge-assisted $\mathrm{N}^{+}-\mathrm{H}^{+} \mathrm{O}^{-}$hydrogen bonds from two NFX molecules to form a centrosymmetrical trimeric unit.

The water molecules are located between the adjacent fumarate ions, uniting the counterions via hydrogen bonding

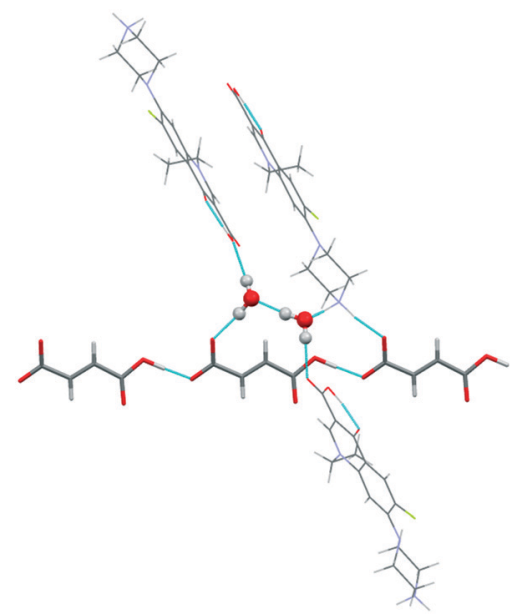

Fig. 3 Illustration of hydrogen bonds in the crystals of [NFX + Fum + $\left.\mathrm{H}_{2} \mathrm{O}\right](1: 1: 2)$.

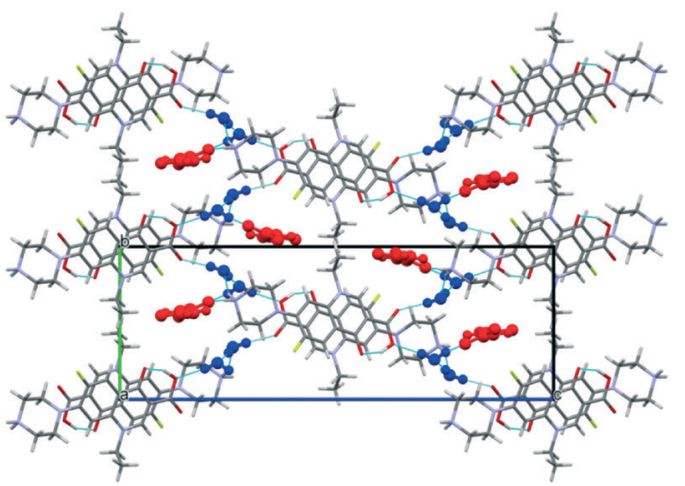

(a)

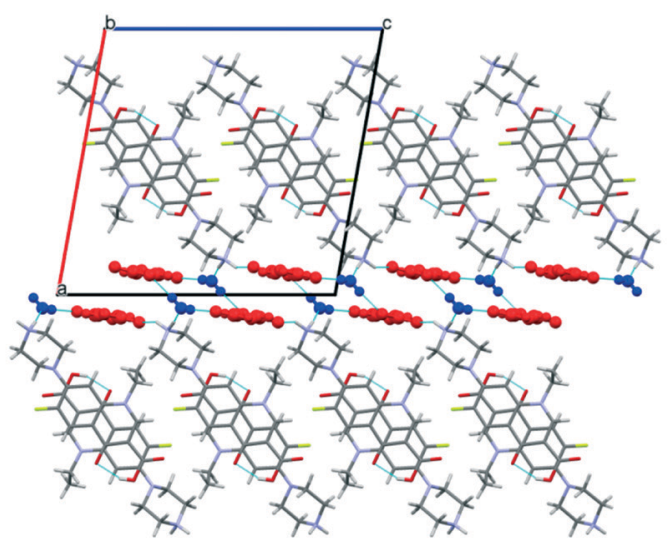

(b)

Fig. 4 Packing arrangement of (a) [NFX + Fum $\left.+\mathrm{H}_{2} \mathrm{O}\right](1: 1: 2)$ and (b) [NFX + Fum $\left.+\mathrm{H}_{2} \mathrm{O}\right](1: 1: 1)$. The fumarate ions are colored red, while the water molecules are colored blue.

into a single layer which is extended along the $a$-axis (Fig. 5a). Interestingly, $\mathrm{H}_{2} \mathrm{O}$ molecules act only as donors of hydrogen bonds, while the water oxygen does not seem to get involved in strong interactions. As seen in Fig. $4 \mathrm{~b}$ and $5 \mathrm{~b}$, the crystals of $\left[\mathbf{N F X}+\right.$ Fum $\left.+\mathbf{H}_{2} \mathbf{O}\right](1: 1: 1)$ and $[\mathbf{N F X}+$ Fum + $\mathrm{H}_{2} \mathrm{O}$ ] $(1: 0.5: 1)$ have some common packing features. In both forms, the NFX ions are arranged in structurally almost identical $\pi$-stacks, separated by layers of counterions and water molecules. This leads to the suggestion that the spatial arrangement of NFX in these crystals is favorable in terms of packing energy, and it can play the role of a supramolecular framework, allowing counterions and water molecules to be placed in different ways within the framework. This assumption is supported by the fact that the $\left[\mathbf{N F X}+\right.$ Fum $\left.+\mathbf{H}_{2} \mathbf{O}\right]$ (1: $0.5: 1)$ salt is found to have an isostructural counterpart, namely norfloxacin succinate monohydrate ([NFX + succinic $\left.+\mathrm{H}_{2} \mathrm{O}\right](1: 0.5: 1)$ - VETWAT, Fig. S9†). Taking into account that (i) isomorphism is quite a rare event among fluoroquinolone multi-component crystals and (ii) there is no evidence that there are other forms of $\left[\mathrm{NFX}+\right.$ succinic $\left.+\mathrm{H}_{2} \mathrm{O}\right]$ (1: 0.5 : $1),{ }^{7}$ it can be concluded that the packing arrangement of NFX ions in the fumarate and succinate salts is associated with the low Gibbs free energy value and is, therefore, more stable than all possible alternatives. 


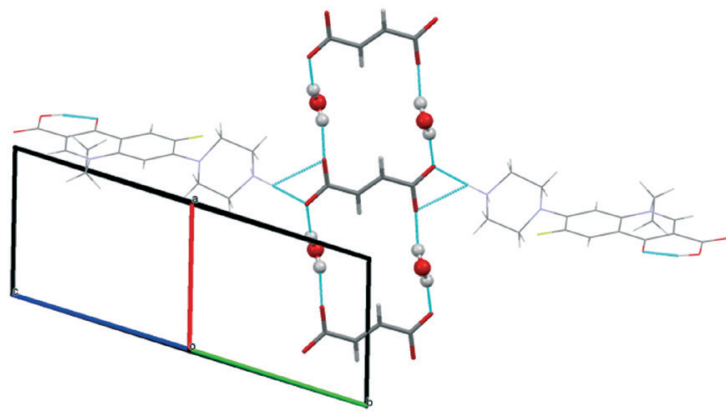

(a)

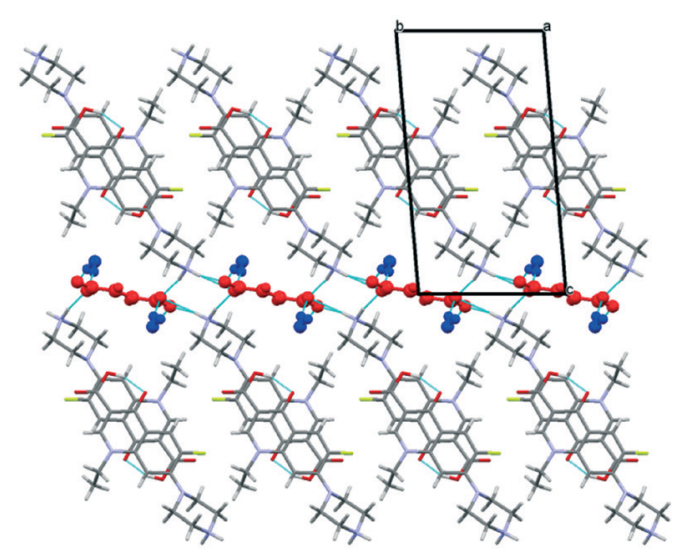

(b)

Fig. 5 Illustration of (a) hydrogen bonds and (b) molecular packing projection in the [NFX + Fum $+\mathrm{H}_{2} \mathrm{O}$ ] $(1: 0.5: 1)$ salt. The fumarate ions are colored red, the water molecules are colored blue.

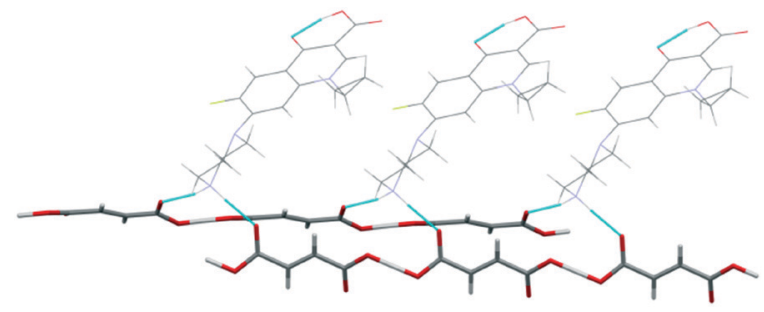

(a)

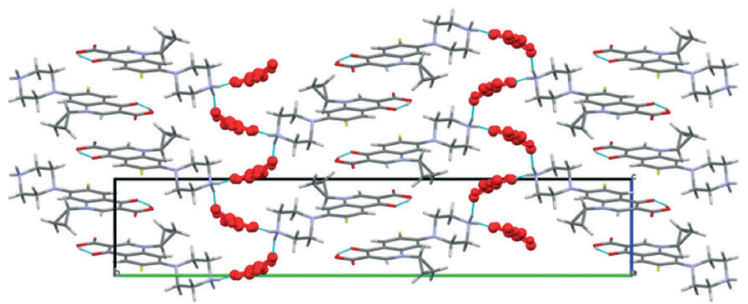

(b)

Fig. 6 Illustration of (a) hydrogen bonds and (b) molecular packing projection in the [CIP + Fum] $(1: 1)$ salt. The fumarate ions are colored red.

According to single-crystal X-ray data, the [CIP + Fum] (1: 1) salt sample obtained by solution crystallization contained
0.16 water molecules per 1 molecule of the salt. Nevertheless, the water molecules do not play a significant role in the crystal structure, as seen in Fig. S10, $\uparrow$ forming only two weak $\left(D_{\mathrm{O} \cdots \mathrm{O}}>2.9 \AA, D_{\mathrm{H} \cdots \mathrm{O}}>2.2 \AA\right)$ hydrogen bonds with neighbouring fumarate ions, and thus can be considered as inclusions of crystallization water. The calculated PXRD pattern from the crystal structure was found to be in an excellent agreement with the experimental one for the anhydrous salt, indicating that single crystal X-ray data is consistent with the bulk material generated by grinding (Fig. S7†). As in the systems described above, in the [CIP + Fum] (1:1) crystal, the fumarate ions are connected by short $\left(D_{\mathrm{O}} \cdots \mathrm{O}>2.47 \AA, D_{\mathrm{H} \cdots \mathrm{O}}\right.$ $>1.35 \AA$ ) hydrogen bonds to form infinite chains with the $\mathrm{C}(7)$ graph set notation. Each CIP cation is involved in hydrogen bonding with two neighbouring chains, which are extended at an angle of $\approx 47^{\circ}$ to each other (Fig. 6a). The packing arrangement of the salt consists of alternating layers containing the conventional $\pi$-stacks of CIP and the perpendicularly oriented hydrogen bonded chains of the acid (Fig. 6b).

The asymmetric unit of the $\left[\mathrm{CIP}+\mathrm{Fum}+\mathrm{H}_{2} \mathrm{O}\right](1: 0.5: 1.5)$ salt contains two cations of the drug, one anion of the acid and three water molecules. Both of the carboxylic groups of fumaric acid are deprotonated and accept multiple hydrogen bonds. There are nine $\mathrm{H}$-bonds from the surrounding CIP cations and water molecules per fumaric dianion. Two of the three water molecules in the structure act as linkers between the separate fumarate ions, while the third one connects the carboxylic groups of ciprofloxacin to the counterion (Fig. S11a $\dagger$ ). The components of the salt are packed in a conventional layer-like manner, which is characterised by alternating hydrophobic and hydrophilic regions containing the fluoroquinolone moieties and hydrated dianions of fumaric acid, respectively (Fig. S11b $\dagger$ ).

\subsection{Thermal analysis}

The DSC traces for ciprofloxacin and norfloxacin fumarates are shown in Fig. 7, and the thermal data are presented in Table 2. For all the salt hydrates, the first endothermic event in the DSC curves corresponds to the dehydration process, which is followed by melting of the unhydrated product (Fig. 7). The highest dehydration temperature $\left(T_{\text {dehyd }}\right)$ is observed for the $\left[\mathbf{C I P}+\right.$ Fum $\left.+\mathbf{H}_{2} \mathbf{O}\right](1: 1: 1)$ form, which is thermally stable up to $140{ }^{\circ} \mathrm{C}$. All the hydrated salts of norfloxacin fumarate, however, start to release the solvent at a considerably lower temperature $\left(\approx 40-50{ }^{\circ} \mathrm{C}\right)$. The dehydration process of $\left[\mathrm{CIP}+\mathrm{Fum}+\mathrm{H}_{2} \mathrm{O}\right](1: 0.5: 1.5)$ is characterised by an asymmetric peak on the DSC curve and variable steepness of the TG mass loss (Fig. S12 $\dagger$ ), suggesting a stepwise process of the solvent release. It is interesting to note that all bulk samples of [CIP + Fum] (1:1) obtained by grinding show no dehydration in DSC analysis (Fig. S5†), while the single crystals were found to contain 0.16 water molecules per asymmetric unit. This along with the low binding of water molecules with the crystal surroundings allows 


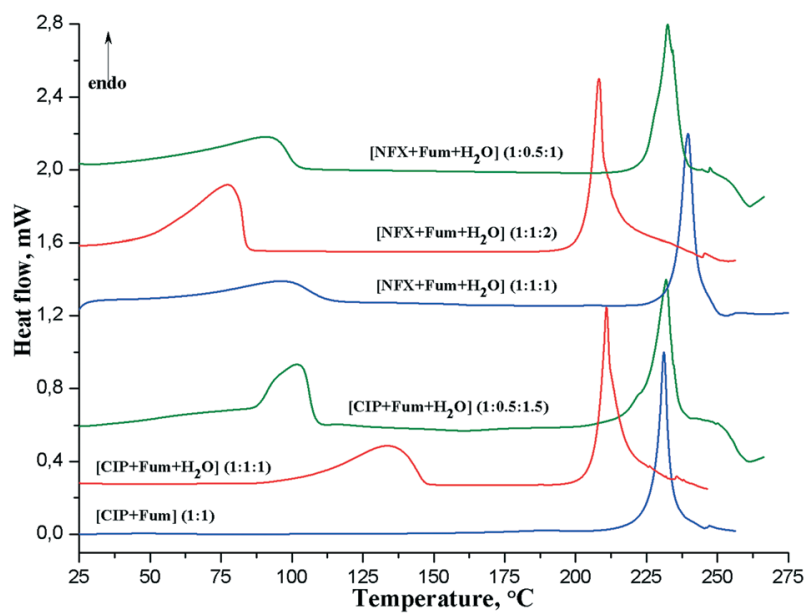

Fig. 7 DSC curves for different forms of ciprofloxacin and norfloxacin fumarates recorded at a $10^{\circ} \mathrm{C} \mathrm{min}-1$ heating rate.

one to attribute the 0.16 molecules of $\mathrm{H}_{2} \mathrm{O}$ to the water of crystallization.

The large difference between the thermal stability of the hydrates indicates that the interaction energies between the solvent molecules and the host structure of the salts are different. The binding strength of the solvent in the hydrated salts can be estimated by calculating the enthalpy of vaporization $\left(\Delta H_{\mathrm{S}}\right)$ of the salt-bound solvent using the following relationship: ${ }^{34}$

$$
\Delta H_{\mathrm{S}}=\left(\Delta H_{\mathrm{desolv}}^{T} \times 100 / \Delta m_{\mathrm{S}}\right) \cdot M_{\mathrm{S}}
$$

where $\Delta H_{\text {desolv }}^{T}$ is the enthalpy of desolvation/dehydration derived from the DSC data, $\Delta m_{\mathrm{S}}$ is the percent mass loss measured in the TG experiment, and $M_{\mathrm{S}}$ is the molecular weight of the solvent.

The resulting $\Delta H_{\mathrm{S}}$ values for the solvates are shown in Table 2. It is evident that in [CIP + Fum $\left.+\mathbf{H}_{2} \mathbf{O}\right](1: 1: 1)$, the water molecules are more tightly bound to the host structure than those in $\left[\mathbf{N F X}+\mathbf{F u m}+\mathbf{H}_{2} \mathbf{O}\right](1: 1: 1)$, resulting in an unusually high dehydration temperature of the former salt. Despite the relatively small $T_{\text {dehyd }}$ values of the norfloxacin fumarate hydrates, the $\Delta H_{\mathrm{S}}$ parameter indicates stronger interactions of $\mathrm{H}_{2} \mathrm{O}$ molecules with the salt crystal environment than in the pure liquid (vaporization enthalpy of water, $\left.\approx 40.7 \mathrm{~kJ} \mathrm{~mol}^{-1}\right)$. In the $\left[\mathrm{CIP}+\right.$ Fum $\left.+\mathrm{H}_{2} \mathrm{O}\right](1: 0.5: 1.5)$ salt, however, the $\Delta H_{\mathrm{S}}$ value is comparable with the enthalpy of pure water vaporization.

The DSC data also show that the products of the salt dehydration have different melting temperatures (Table 2). For example, the dehydrated forms of $\left[\mathrm{NFX}+\mathrm{Fum}+\mathbf{H}_{2} \mathrm{O}\right](1: 1: 1)$ and $\left[\mathrm{NFX}+\right.$ Fum $\left.+\mathrm{H}_{2} \mathrm{O}\right](1: 1: 2)$ can be considered as two polymorphs of anhydrous norfloxacin fumarate. Interestingly, the temperature and enthalpy of the melting process of the monohydrate form which is less stable at room temperature are higher than those of the $\left[\mathbf{N F X}+\mathbf{F u m}+\mathbf{H}_{2} \mathbf{O}\right](1: 1: 2)$ salt. According to the $\Delta H_{\text {fus }}$ values, when dehydrated, most of the salts remained highly crystalline materials. For [CIP + Fum + $\left.\mathbf{H}_{2} \mathrm{O}\right](1: 0.5: 1.5)$ and $\left[\mathrm{NFX}+\mathrm{Fum}+\mathrm{H}_{2} \mathrm{O}\right](1: 0.5: 1)$, however, loss of solvent molecules reduced the crystallinity of the salts and decreased the melting heat effect. However, the dehydration products were found to be hydroscopic when exposed to air for several minutes, regaining the missing water content, making them unable to be characterised by X-ray diffraction methods.

\subsection{Relative stability of the solid forms and determination of the critical water activity.}

It has been established that the temperature and water content in the surrounding medium are the key factors that determine the relative stability of the anhydrous and hydrated forms of a compound. ${ }^{35-37}$ At constant temperature, the formation of the hydrated form from anhydrous crystals may be represented by the following equilibrium: ${ }^{38}$

$$
\begin{gathered}
A_{\text {solid }}+n \mathrm{H}_{2} \mathrm{O} \leftrightarrow A \cdot n \mathrm{H}_{2} \mathrm{O}_{\text {solid }} \\
K_{\mathrm{h}}=\frac{a\left(A \cdot n \mathrm{H}_{2} \mathrm{O}_{\text {solid }}\right)}{a\left(A_{\text {solid }}\right) \cdot a\left(\mathrm{H}_{2} \mathrm{O}\right)^{n}}=a\left(\mathrm{H}_{2} \mathrm{O}\right)^{-n}
\end{gathered}
$$

where $K_{\mathrm{h}}$ is the equilibrium constant for the process, and $a\left(A \cdot n \mathrm{H}_{2} \mathrm{O}_{\text {solid }}\right), a\left(A_{\text {solid }}\right)$, and $a\left(\mathrm{H}_{2} \mathrm{O}\right)$ are the thermodynamic activities of the hydrate, the anhydrate, and water, respectively. When $K_{\mathrm{h}}>1$, the hydrate is more stable than the anhydrate. The anhydrate is more stable than the hydrate in the inverse situation. If the standard states of unit activity of $A_{\text {solid }}$ and of $A \cdot n \mathrm{H}_{2} \mathrm{O}_{\text {solid }}$ are represented by their pure solid phases, eqn (4) can be simplified as shown above. The equilibrium water

\begin{tabular}{|c|c|c|c|c|c|c|}
\hline & $T_{\text {dehyd }},{ }^{\circ} \mathrm{C}$ & $\Delta H_{\text {dehyd }}, \mathrm{J} \mathrm{g}^{-1}$ & $\Delta m_{\mathrm{S}}, \%$ & $T_{\text {fus }},{ }^{\circ} \mathrm{C}$ & $\Delta H_{\text {fus }}, \mathrm{J} \mathrm{g}^{-1}$ & $\Delta H_{\mathrm{S}}, \mathrm{kJ} \mathrm{mol}^{-1}$ \\
\hline$\left[\mathrm{NFX}+\mathrm{Fum}+\mathrm{H}_{2} \mathrm{O}\right](1: 1: 1)$ & $83.1 \pm 1.5$ & $129.0 \pm 4.0$ & 3.90 & $229.0 \pm 2.0$ & $230.0 \pm 4.0$ & 58.7 \\
\hline$\left[\mathrm{NFX}+\right.$ Fum $\left.+\mathrm{H}_{2} \mathrm{O}\right](1: 0.5: 1)$ & $89.3 \pm 1.5$ & $131.3 \pm 2.0$ & 4.65 & $227.1 \pm 2.0$ & $148.3 \pm 3.0$ & 51.9 \\
\hline CIP & & & & 271.0 & & \\
\hline$\left[\mathrm{CIP}+\mathbf{F u m}+\mathbf{H}_{2} \mathrm{O}\right]^{a}(1: 1: 1)$ & $141.0 \pm 0.8$ & $156.5 \pm 4.0$ & 3.90 & $203.8 \pm 0.9$ & $216.7 \pm 5.0$ & 72.8 \\
\hline$\left[\mathrm{CIP}+\right.$ Fum $\left.+\mathrm{H}_{2} \mathrm{O}\right](1: 0.5: 1.5)$ & $102.5 \pm 2.0$ & $137.8 \pm 4.5$ & 6.20 & $226.7 \pm 3.0$ & $117.5 \pm 4.0$ & 38.3 \\
\hline
\end{tabular}
activity for an anhydrate/hydrate system is usually designated

Table 2 Thermophysical data for ciprofloxacin and norfloxacin fumarates

${ }^{a}$ The data is taken from ref. 8 . 
as the critical water activity $\left(a_{\mathrm{w}}^{\mathrm{c}}\right)$. Since $K_{\mathrm{h}}$ is known at a particular temperature, the standard free-energy change for the hydration reaction can be calculated using the following expression:

$$
\Delta G_{\mathrm{h}}^{0}=-R T \cdot \ln K_{\mathrm{h}}=-R T \cdot \ln \frac{1}{a\left(\mathrm{H}_{2} \mathrm{O}\right)^{n}}
$$

In order to establish the thermodynamic stability ranges of the different crystalline forms of ciprofloxacin and norfloxacin fumarates, solubility experiments in water/methanol mixtures of various compositions were performed. The details of the experimental procedure are provided in the Materials and methods section.

The phase solubility diagram for the ciprofloxacin fumarate salts as a function of water activity $\left(a_{\mathrm{w}}\right)$ in water/methanol mixtures is shown in Fig. 8. Anhydrous [CIP + Fum] (1:1) was used as the starting phase in all the experiments. Analysis of the residual phases revealed that [CIP + Fum] (1:1) remained stable at a water activity $a_{\mathrm{w}}$ of $<0.42$. At $a_{\mathrm{w}}>0.44$, the $\left[\mathbf{C I P}+\right.$ Fum $\left.+\mathbf{H}_{2} \mathbf{O}\right](1: 1: 1)$ salt was the only solid phase at equilibrium, suggesting that the equilibrium (critical) water activity of the transition from anhydrous form to monohydrate was about 0.43 . According to eqn (5), the Gibbs energy of the hydration process was calculated to be $-2.0 \mathrm{~kJ}$ $\mathrm{mol}^{-1}$.

As Fig. 8 shows, the value of the equilibrium water activity corresponds to the maximum of the salt solubility in the mixture. It is evident that the presence and position of this maximum is a consequence of various factors, including the solid state of the equilibrium phase and solvation of ciprofloxacin and the counterion in the water/methanol solution. This issue, however, is beyond the scope of the current work. In order to verify the stability range of [CIP + Fum] (1:1), the slurries of the anhydrous salt were seeded with [CIP + Fum + $\left.\mathrm{H}_{2} \mathrm{O}\right](1: 1: 1)$ at several $a_{\mathrm{w}}<0.43$ points and left to equili-

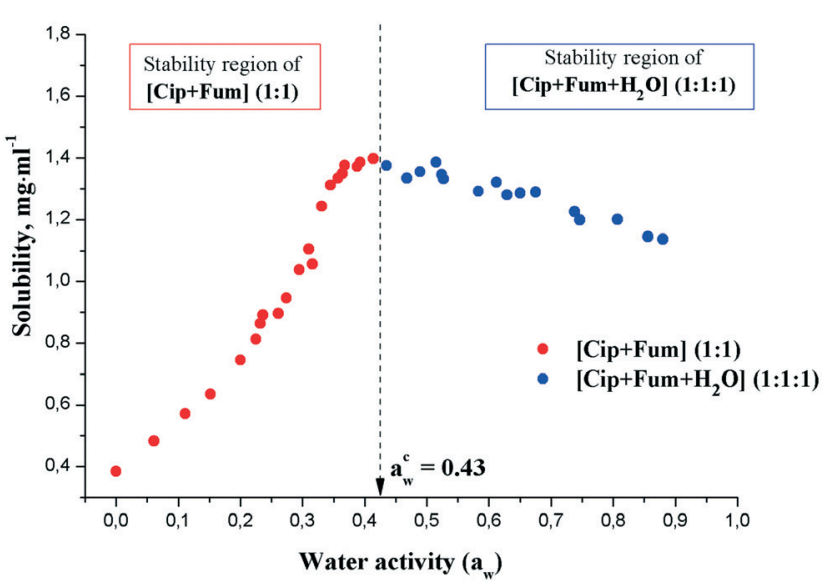

Fig. 8 Phase diagram showing the dependence of ciprofloxacin fumarate solubility on water activity in methanol/water mixtures at 25 ${ }^{\circ} \mathrm{C}$. Anhydrous [CIP + Fum] (1:1) was used as the starting phase; the residual phase was determined with PXRD. brate for 3 days. However, no evidence of a phase transition was observed, confirming the thermodynamic stability of the [CIP + Fum] $(1: 1)$ form in the tested $a_{\mathrm{w}}$ region.

In the case of NFX salts, the initial phase for the solubility experiments was $\left[\mathbf{N F X}+\mathbf{F u m}+\mathbf{H}_{2} \mathbf{O}\right](1: 1: 1)$. The phase transitions between the hydrates of the norfloxacin fumarates are not straightforward compared to the anhydrate/hydrate of ciprofloxacin fumarate. As Fig. 9 indicates, the $[$ NFX + Fum + $\left.\mathbf{H}_{2} \mathrm{O}\right]$ (1:1:1) form was stable until the water activity reached a value of $a_{\mathrm{w}}=0.33$. However, a further increase in $a_{\mathrm{w}}$ resulted in the transformation of fumarate monohydrate $(1$ : $1: 1)$ into hemifumarate monohydrate $(1: 0.5: 1)$. However, the $\left[\mathrm{NFX}+\mathrm{Fum}+\mathrm{H}_{2} \mathrm{O}\right](1: 1: 1) \rightarrow\left[\mathrm{NFX}+\mathrm{Fum}+\mathrm{H}_{2} \mathrm{O}\right](1: 1:$ 2) phase transition would be more expected in this case. PXRD analysis of the residual materials revealed that $[\mathrm{NFX}+$ Fum $+\mathbf{H}_{2} \mathrm{O}$ ] (1: $\left.0.5: 1\right)$ was the only solid phase at the equilibrium up to $a_{\mathrm{w}}=0.74$. At $a_{\mathrm{w}}>0.76$, the $\left[\mathrm{NFX}+\mathbf{F u m}+\mathbf{H}_{2} \mathbf{O}\right]$ $(1: 1: 2)$ hydrate was found to be the most thermodynamically stable form.

The results suggest alternative transformation pathways of the $\left[\mathbf{N F X}+\right.$ Fum $\left.+\mathbf{H}_{2} \mathbf{O}\right](1: 1: 1)$ form as a function of solvent composition. It seems that spontaneous transition of the norfloxacin fumarate monohydrate to dihydrate occurs only in a water-rich region of the methanol/water mixture $\left(a_{\mathrm{w}}>\right.$ 0.76). At water activities less than 0.76 , the $[\mathbf{N F X}+$ Fum + $\left.\mathrm{H}_{2} \mathrm{O}\right](1: 1: 1) \rightarrow\left[\mathrm{NFX}+\mathrm{Fum}+\mathrm{H}_{2} \mathrm{O}\right](1: 0.5: 1)$ transition becomes thermodynamically favored.

A similar phenomenon has been recently described by Tieger et $a .^{39}$ for different polymorphic forms of sitagliptin L-tartrate, the stability order of which altered depending on the $a_{\mathrm{w}}$ value of the water/organic mixture.

To make sure that the $\left[\mathrm{NFX}+\right.$ Fum $\left.+\mathrm{H}_{2} \mathrm{O}\right](1: 1: 1) \rightarrow$ $\left[\mathrm{NFX}+\right.$ Fum $\left.+\mathrm{H}_{2} \mathrm{O}\right](1: 0.5: 1)$ phase transition depends solely on water activity and is not affected by the organic solvent, $\left[\mathrm{NFX}+\right.$ Fum $\left.+\mathrm{H}_{2} \mathrm{O}\right](1: 1: 1)$ was slurried in two water/alcohol mixtures $\left(\mathrm{EtOH} / \mathrm{H}_{2} \mathrm{O},{ }^{40} \mathrm{IPA} / \mathrm{H}_{2} \mathrm{O}^{31}\right)$ with a constant $a_{\mathrm{w}}$ value equaling 0.5 . The subsequent PXRD analysis showed that in both mixtures the transformation of fumarate

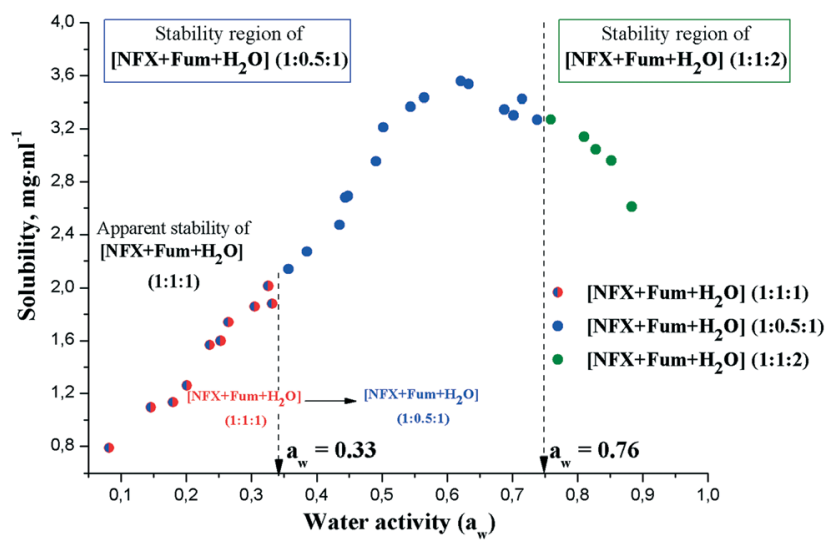

Fig. 9 Phase diagram showing the dependence of norfloxacin fumarate solubility on water activity in methanol/water mixtures at 25 ${ }^{\circ} \mathrm{C}$. The [NFX + Fum $\left.+\mathrm{H}_{2} \mathrm{O}\right](1: 1: 1)$ form was used as the starting phase; the residual phase was determined with PXRD. 
monohydrate $(1: 1: 1)$ to hemifumarate monohydrate $(1: 0.5$ : 1) took place (Fig. S13 $\uparrow$ ), confirming the fact that water activity is the major factor determining the nucleation and growth of the $\left[\mathrm{NFX}+\right.$ Fum $\left.+\mathrm{H}_{2} \mathrm{O}\right](1: 0.5: 1)$ phase.

As the next step, we analysed the influence of $[\mathrm{NFX}+$ Fum $\left.+\mathrm{H}_{2} \mathrm{O}\right](1: 0.5: 1)$ additives (seeds) on $\left[\mathrm{NFX}+\mathbf{F u m}+\mathrm{H}_{2} \mathrm{O}\right](1$ : $1: 1)$ hydrate stability. The slurries of the $\left[\mathbf{N F X}+\right.$ Fum $\left.+\mathbf{H}_{2} \mathbf{O}\right]$ $(1: 1: 1)$ salt were seeded with a small amount of $[$ NFX + Fum $\left.+\mathrm{H}_{2} \mathrm{O}\right](1: 0.5: 1)$ at several $a_{\mathrm{w}}<0.43(0.10,0.14,0.21,0.25$, $0.30)$ points and left to equilibrate for 3 days. It was observed that addition of the hemifumarate monohydrate $(1: 0.5: 1)$ promoted the $\left[\mathbf{N F X}+\right.$ Fum $\left.+\mathbf{H}_{2} \mathbf{O}\right](1: 1: 1) \rightarrow[\mathbf{N F X}+$ Fum + $\mathrm{H}_{2} \mathrm{O}$ ] (1:0.5:1) phase transition at all the studied compositions. This observation indicates that $\left[\mathbf{N F X}+\mathbf{F u m}+\mathbf{H}_{2} \mathbf{O}\right]$ (1: $1: 1)$ is a less thermodynamically stable form than [NFX + Fum $+\mathbf{H}_{2} \mathrm{O}$ ] (1 : 0.5 : 1). However, similar seeding experiments at $a_{\mathrm{w}}>0.76$ had no influence on the transformation pathway of the fumarate monohydrate $(1: 1: 1)$, i.e. $[\mathrm{NFX}+$ Fum + $\left.\mathrm{H}_{2} \mathrm{O}\right](1: 1: 1) \rightarrow\left[\mathrm{NFX}+\mathrm{Fum}+\mathrm{H}_{2} \mathrm{O}\right](1: 1: 2)$.

Based on the experimental results, it is possible to rationalise the thermodynamic stability relationship between different hydrates of the norfloxacin fumarates. The $[\mathbf{N F X}+$ Fum $\left.+\mathrm{H}_{2} \mathrm{O}\right](1: 1: 1)$ salt was found to be metastable at all $a_{\mathrm{w}}$ values. The apparent long-term stability of this form at $a_{\mathrm{w}}<$ 0.33 seems likely to be due to the low solubility of the salt (Fig. 11) which results in a high activation barrier of nucleation of the stable phase, i.e. $\left[\mathrm{NFX}+\mathrm{Fum}+\mathrm{H}_{2} \mathrm{O}\right](1: 0.5: 1)$. The seeding of $\left[\mathbf{N F X}+\mathbf{F u m}+\mathbf{H}_{2} \mathbf{O}\right](1: 1: 1)$ solutions with the stable form diminishes the nucleation barrier and makes the phase transformation possible even at $a_{\mathrm{w}}=0.1$. With an increase in water activity, the solute-solvent interaction accelerates the nucleation and growth rate of hemifumarate monohydrate $(1: 0.5: 1)$, leading to a spontaneous $[\mathrm{NFX}+$ Fum $\left.+\mathrm{H}_{2} \mathrm{O}\right](1: 1: 1) \rightarrow\left[\mathrm{NFX}+\right.$ Fum $\left.+\mathrm{H}_{2} \mathrm{O}\right](1: 0.5: 1)$ transition at $a_{\mathrm{w}}>0.33$. In a water-rich region of the methanol/water mixture $\left(a_{\mathrm{w}}>0.76\right)$, the formation of the [NFX + Fum + $\mathrm{H}_{2} \mathrm{O}$ ] (1:1:2) form is thermodynamically preferred, resulting

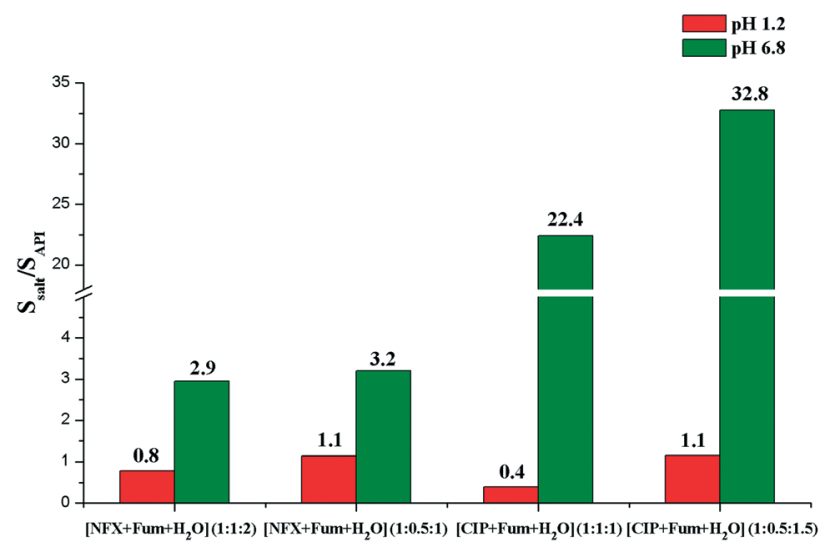

Fig. 11 Relative solubilities of stable salts at $\mathrm{pH} 1.2$ and $\mathrm{pH} 6.8(25.0$ $\left.{ }^{\circ} \mathrm{C}\right)$.

in fumarate monohydrate transition to a dihydrate. Therefore, by carefully choosing $a_{\mathrm{w}}$ (solution composition), it is possible to crystallise three hydrates of the norfloxacin fumarates; otherwise, concomitant crystallisation of solid forms may be observed. Moreover, water activity is the major factor that determines the outcome of the liquid-assisted grinding reaction (see 3.1), leading to the selective formation of [CIP + Fum] $(1: 1)$ and $\left[\mathbf{N F X}+\mathbf{F u m}+\mathbf{H}_{2} \mathbf{O}\right](1: 1: 1)$ in the presence of solvent mixtures with low $a_{\mathrm{w}}$, and yielding [CIP + Fum + $\left.\mathbf{H}_{2} \mathbf{O}\right](1: 1: 1)$ and $\left[\mathbf{N F X}+\right.$ Fum $\left.+\mathbf{H}_{2} \mathbf{O}\right](1: 1: 2)$ at high $a_{\mathrm{w}}$ values.

\subsection{Solution stability, solubility and dissolution rate of ciprofloxacin and norfloxacin fumarates}

The aim of the next part of this work was to explore the influence of crystal structure and hydration level of the ciprofloxacin and norfloxacin fumarates on their stability and solubility in aqueous solutions with pharmaceutically relevant $\mathrm{pH}$ values (1.2 and 6.8) at $25{ }^{\circ} \mathrm{C}$. The solid form stability at

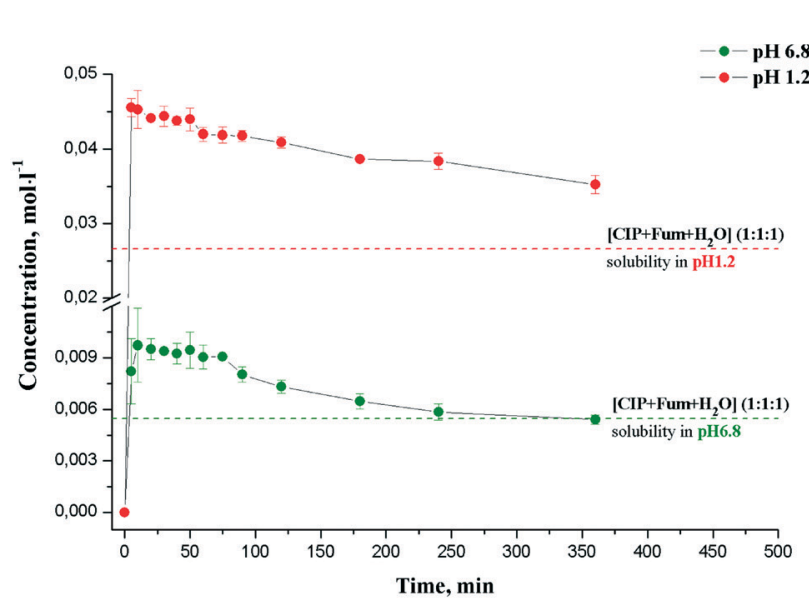

(a)

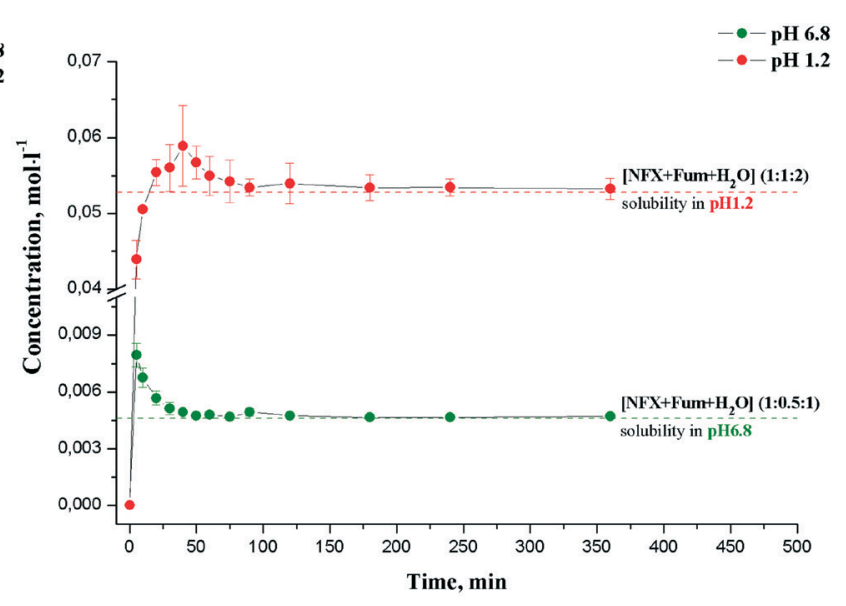

(b)

Fig. 10 Dissolution profiles and transformation pathways for (a) [CIP + Fum] (1:1) and (b) [NFX + Fum $\left.+\mathrm{H}_{2} \mathrm{O}\right](1: 1: 1)$ in the pH 1.2 and pH 6.8 solutions at $25^{\circ} \mathrm{C}$. 
different $\mathrm{pH}$ values was monitored by analyzing samples from the bottom phase after 6 hours of shaking, using PXRD. If a phase transformation was detected, the corresponding salt was further investigated by the powder dissolution method (Fig. 10). The solubility values of the congruently soluble forms were measured after 24 and 48 hours of dissolution (Table 3).

3.4.1 Stability of solid forms at different $\mathrm{pH}$ values. PXRD studies revealed that $[$ CIP + Fum $](1: 1)$ and $[$ NFX + Fum + $\mathrm{H}_{2} \mathrm{O}$ ] (1:1:1) were unstable upon dissolution and underwent a solution-mediated phase transformation during the experiment. The anhydrous [CIP + Fum] (1:1) salt transformed into $\left[\mathbf{C I P}+\right.$ Fum $\left.+\mathrm{H}_{2} \mathrm{O}\right](1: 1: 1)$ at both $\mathrm{pH}$ values (Fig. S14 $\dagger$ ). Interestingly, the transformation pathways of the [NFX + Fum $\left.+\mathrm{H}_{2} \mathrm{O}\right](1: 1: 1)$ form were found to be $\mathrm{pH}$-dependent. At $\mathrm{pH}$ 1.2 , dissolution of fumarate monohydrate $(1: 1: 1)$ resulted in the formation of $\left[\mathrm{NFX}+\mathrm{Fum}+\mathrm{H}_{2} \mathrm{O}\right](1: 1: 2)$. At $\mathrm{pH} 6.8$, however, the $\left[\mathbf{N F X}+\mathbf{F u m}+\mathbf{H}_{2} \mathbf{O}\right](1: 0.5: 1)$ salt was the only solid phase at equilibrium (Fig. S15 $\dagger$ ). Moreover, PXRD analysis of $\left[\mathrm{NFX}+\right.$ Fum $\left.+\mathrm{H}_{2} \mathrm{O}\right](1: 1: 2)$ recovered after 48 hours of dissolution in $\mathrm{pH} 6.8$ medium showed partial transformation of the salt into hemifumarate monohydrate (1:0.5:1) (Fig. $\mathrm{S} 16 \dagger)$. These results suggest that the relative stability of the $\left[\mathrm{NFX}+\right.$ Fum $\left.+\mathrm{H}_{2} \mathrm{O}\right](1: 1: 2)$ and $\left[\mathrm{NFX}+\right.$ Fum $\left.+\mathbf{H}_{2} \mathrm{O}\right](1: 0.5:$ 1) forms depends not only on the water activity in a solvent (see 3.3), but is also affected by the $\mathrm{pH}$ value of the surroundings.

We suppose that the difference in stability of salts with $(1: 1)$ and $(1: 0.5)$ stoichiometries has its origin in the ratio of solubilities of individual components. As is known from the literature, the solubility of pure NFX in mixed water-methanol media at $25{ }^{\circ} \mathrm{C}$ is within $0.02-0.04 \mathrm{mg} \mathrm{L^{-1 }}{ }^{41}$ The solubility of fumaric acid rapidly increases with the amount of methanol in the system from $1.19 \times 10^{-3}$ mole fr. at $x(\mathrm{MeOH})$ $=0.073$ to $2.47 \times 10^{-2}$ mole fr. at $x(\mathrm{MeOH})=0.800 .^{42}$ By comparing these data using the known equations for the density of water-methanol mixtures, ${ }^{43}$ one can observe that the ratio of mole fraction solubilities $x_{\text {Fum }} / x_{\mathrm{NFX}}$ changes from $c a .3600$ at $a_{\mathrm{w}}=0.26$ to only ca. 380 at $a_{\mathrm{w}}=0.92$, i.e. in about ten times. Hence, dissolving $\left[\mathbf{N F X}+\right.$ Fum $\left.+\mathbf{H}_{2} \mathbf{O}\right](1: 1: 1)$ in methanol-rich solutions where the solubility of norfloxacin is three orders lower than that of fumaric acid results in NFX supersaturation and phase transition into the form with a higher API/counterion ratio, i.e. $\left[\mathrm{NFX}+\right.$ Fum $\left.+\mathbf{H}_{2} \mathbf{O}\right]$ (1: 0.5 : 1). In water-rich regions of the phase diagram, the $x_{\mathrm{Fum}} / x_{\mathrm{NFX}}$ ratio is much lower, and $\left[\mathrm{NFX}+\mathrm{Fum}+\mathrm{H}_{2} \mathrm{O}\right](1: 0.5: 1)$ appears to be less stable than dihydrated $\left[\mathbf{N F X}+\mathbf{F u m}+\mathbf{H}_{2} \mathbf{O}\right.$ ] $(1: 1: 2)$. This phenomenon is commonly observed in cocrystals of different API/coformer ratios. ${ }^{44,45}$

A similar tendency is observed when pure NFX and fumaric acid are dissolved in aqueous buffer solutions with different $\mathrm{pH}$ values, ${ }^{46,47}$ with $x_{\mathrm{Fum}} / x_{\mathrm{NFX}}$ values higher in acidic media and lower at neutral $\mathrm{pH}$, leading to greater stability of $\left[\mathbf{N F X}+\mathbf{F u m}+\mathbf{H}_{2} \mathbf{O}\right](1: 0.5: 1)$ in the $\mathrm{pH} 6.8$ solution.

The dissolution profiles for the unstable salts demonstrate the so-called "spring and parachute" behavior ${ }^{48}$ (Fig. 10). It is evident that the transformation rates of the metastable forms of the CIP and NFX fumarates are considerably different. For [CIP + Fum $](1: 1)$ at pH 6.8, it took about 4 hours to complete the transformation into the hydrated form. At $\mathrm{pH} 1.2$, the process lasted more than 7 hours (Fig. 10a). In contrast, formation of $\left[\mathbf{N F X}+\mathbf{F u m}+\mathbf{H}_{2} \mathbf{O}\right](1: 1: 2)$ and $[\mathbf{N F X}+$ Fum $\left.+\mathrm{H}_{2} \mathrm{O}\right](1: 0.5: 1)$ from $\left[\mathrm{NFX}+\mathrm{Fum}+\mathrm{H}_{2} \mathrm{O}\right](1: 1: 1)$ at $\mathrm{pH}$ 1.2 and $\mathrm{pH} 6.8$, respectively, occurred within 1 hour (Fig. 10b).

3.4.2 Solubility of the solid forms at different $\mathrm{pH}$ values. According to long-term dissolution studies, pure NFX at $\mathrm{pH}$ 6.8 was found to be $c a$. 6 times more soluble than the parent CIP, which is in good agreement with the literature data. ${ }^{7,13,46,49,50}$ It is well established that the solubility of a compound is determined by a balance between the solventsolute interactions in a solution (solvation/hydration energy) and the intermolecular interactions in the crystal (lattice energy). Therefore, the notable difference in solubilities of the drugs may be due to the difference in the protected $\mathrm{N}$-groups in the pyridine ring (ethyl in norfloxacin and cyclopropyl in ciprofloxacin). ${ }^{50}$ Taking into consideration the large

Table 3 Solubilities of CIP, NFX and their stable fumarates in the $\mathrm{pH} 6.8$ and $\mathrm{pH} 1.2$ solutions at $25.0^{\circ} \mathrm{C}$ and identification of the solid phases recovered after experiment

\begin{tabular}{|c|c|c|c|c|}
\hline Salt/API & \multicolumn{2}{|l|}{ Solubility $(S), \mathrm{mol} \mathrm{l}^{-1}$} & \multicolumn{2}{|l|}{ Solid phase recovered after $48 \mathrm{~h}$} \\
\hline $\begin{array}{l}\text { CIP } \\
{\left[\mathrm{CIP}+\text { Fum }+\mathrm{H}_{2} \mathrm{O}\right]} \\
(1: 1: 1) \\
{\left[\mathrm{CIP}+\text { Fum }+\mathrm{H}_{2} \mathrm{O}\right]} \\
(1: 0.5: 1.5) \\
\text { NFX } \\
{\left[\mathrm{NFX}+\text { Fum }+\mathrm{H}_{2} \mathrm{O}\right]} \\
(1: 1: 2) \\
{\left[\mathrm{NFX}+\text { Fum }+\mathrm{H}_{2} \mathrm{O}\right]} \\
(1: 0.5: 1) \\
{\left[\mathrm{NFX}+\text { succinic }+\mathrm{H}_{2} \mathrm{O}\right]} \\
(1: 0.5: 1)\end{array}$ & $\begin{array}{l}(2.44 \pm 0.09) \times 10^{-4} \\
(5.50 \pm 0.10) \times 10^{-3} \\
(8.00 \pm 0.20) \times 10^{-3} \\
(1.60 \pm 0.05) \times 10^{-3} \\
(4.80 \pm 0.10) \times 10^{-3} \\
(5.14 \pm 0.09) \times 10^{-3} \\
(5.24 \pm 0.10) \times 10^{-3}\end{array}$ & $\begin{array}{l}(6.50 \pm 0.10) \times 10^{-2} \\
(2.65 \pm 0.08) \times 10^{-2} \\
(7.70 \pm 0.20) \times 10^{-2} \\
(6.80 \pm 0.10) \times 10^{-2} \\
(5.30 \pm 0.10) \times 10^{-2} \\
(7.90 \pm 0.30) \times 10^{-2}\end{array}$ & $\begin{array}{l}\text { CIP hydrate } \\
{\left[\mathrm{CIP}+\text { Fum }+\mathrm{H}_{2} \mathrm{O}\right](1: 1: 1)} \\
{\left[\mathrm{CIP}+\text { Fum }+\mathrm{H}_{2} \mathrm{O}\right](1: 0.5: 1.5)} \\
\text { NFX hydrate } \\
\text { Mixture of }\left[\mathrm{NFX}+\mathrm{Fum}+\mathrm{H}_{2} \mathrm{O}\right](1: 1: 2) \text { and } \\
{\left[\mathrm{NFX}+\text { Fum }+\mathrm{H}_{2} \mathrm{O}\right](1: 0.5: 1)} \\
{\left[\mathrm{NFX}+\text { Fum }+\mathrm{H}_{2} \mathrm{O}\right](1: 0.5: 1)} \\
{\left[\mathrm{NFX}+\text { succinic }+\mathrm{H}_{2} \mathrm{O}\right](1: 0.5: 1)}\end{array}$ & $\begin{array}{l}\text { CIP hydrate } \\
{\left[\mathrm{CIP}+\text { Fum }+\mathrm{H}_{2} \mathrm{O}\right]} \\
(1: 1: 1) \\
{\left[\mathrm{CIP}+\text { Fum }+\mathrm{H}_{2} \mathrm{O}\right]} \\
(1: 0.5: 1.5) \\
\text { NFX hydrate } \\
{\left[\mathrm{NFX}+\text { Fum }+\mathrm{H}_{2} \mathrm{O}\right]} \\
(1: 1: 2) \\
{\left[\mathrm{NFX}+\text { Fum }+\mathrm{H}_{2} \mathrm{O}\right]} \\
(1: 0.5: 1)\end{array}$ \\
\hline
\end{tabular}


difference in the melting points of the compounds (more than $50{ }^{\circ} \mathrm{C}$, Table 2), the higher solubility of NFX may also be a consequence of the lower crystal lattice energy of the drug. In this case, however, the apparent solubility data correspond to hydrated forms of the drugs rather than anhydrous compounds. This fact introduces additional complexity to the system and hinders interpretation. As Table 3 shows, salt formation diminishes the difference in the NFX and CIP solubilities in pH 6.8 medium. Nevertheless, the relative solubilities $\left(S_{\text {salt }} / S_{\mathrm{API}}\right)$ of the CIP-based salts are significantly higher than those for the NFX-based salts. The solubility advantage of $\left[\mathbf{C I P}+\mathbf{F u m}+\mathbf{H}_{2} \mathbf{O}\right](1: 1: 1)$ reaches $\approx 22$ times that of the parent drug level, while the most soluble NFX salt $\left(\left[\mathrm{NFX}+\right.\right.$ Fum $\left.\left.+\mathrm{H}_{2} \mathrm{O}\right](1: 0.5: 1)\right)$ shows a moderate 3 -fold enhancement in the solubility (Fig. 11). The relatively small solubility advantage of the NFX salts can be explained by an insignificant decrease in the lattice energy compared to pure NFX. In fact, the melting temperatures of the norfloxacin fumarates are generally comparable with $T_{\text {fus }}$ of the parent drug (Table 2). All CIP salts, however, melt at a lower temperature than pure CIP.

The largest value of the relative solubility $(\approx 33$ times $)$ in $\mathrm{pH} 6.8$ medium is observed for the $\left[\mathrm{CIP}+\right.$ Fum $\left.+\mathbf{H}_{2} \mathbf{O}\right]$ (1: $0.5: 1.5)$ salt (Fig. 11), which is in agreement with the results obtained by Zhang et al. ${ }^{12}$ This result may be a consequence of the following factors: (i) better hydration of the fumarate dianion compared to the monoanion; (ii) loosely bound water molecules in the $\left[\mathbf{C I P}+\right.$ Fum $\left.+\mathbf{H}_{2} \mathrm{O}\right](1: 0.5: 1.5)$ crystal, which are likely to diffuse easily between the crystal lattice and solution.

The obtained data suggest that the crystal structure is the key factor that determines solubility of the salts at $\mathrm{pH}$ 6.8. The result is quite expected in this case as all the studied salts have different packing arrangements, and yet contain the same counterion. The latter allowed us to assume that the hydration contribution to salt solubility is approximately constant (at least for the salts with the same API/fumaric molar ratio). Therefore, it would be interesting to analyse the reverse situation in order to estimate the influence of counterion replacement on salt solubility provided that the packing arrangement of the salt is preserved. Such an analysis can be performed using two isostructural NFX salts, i.e. $\left[\mathbf{N F X}+\right.$ Fum $\left.+\mathbf{H}_{2} \mathbf{O}\right]$ $(1: 0.5: 1)$ and $\left[\mathrm{NFX}+\right.$ succinic $\left.+\mathbf{H}_{2} \mathbf{O}\right](1: 0.5: 1)$ (Fig. S9†).

The solubility of succinic acid in water is about one order of magnitude higher than that of fumaric acid, ${ }^{51}$ partially due to the difference in hydration. If we assume that the counterion hydration has a significant effect on salt solubility, then $\left[\mathbf{N F X}+\right.$ succinic $\left.+\mathbf{H}_{2} \mathbf{O}\right](1: 0.5: 1)$ should be more soluble than $\left[\mathbf{N F X}+\mathbf{F u m}+\mathbf{H}_{2} \mathbf{O}\right](1: 0.5: 1)$. The experimental data indicate that the solubilities of the fumarate and succinate salts at $\mathrm{pH} \quad 6.8$ are closely comparable (Table 3) suggesting that counterion replacement has less impact on the salt solubility compared to the alteration in the crystal structure.

In contrast to the $\mathrm{pH} 6.8$ medium, the solubility values of CIP and NFX in an acidic pH 1.2 buffer solution are similar, indicating a significant increase in hydration energy of the protonated species. It is evident that the solubility of the salts is mainly determined by solvent-solute interactions in a solution (hydration term), while the crystal structure plays a much less important role under the current conditions. A small solubility improvement compared to the parent drugs is observed only in the salts which contain a dianion of fumaric acid (2:1 molar ratio). The fumarates, however, have relative solubility values below one (Table 3, Fig. 11).

3.4.3 Intrinsic dissolution rate (IDR) of the solid forms. As the next step, we measured the dissolution rate of different solid forms of the fumarates. All experiments were conducted in an acidic medium ( $\mathrm{pH}$ 1.2). It has been previously reported that IDR studies on fluoroquinolone salts at neutral $\mathrm{pH}(\mathrm{pH}$ 6.8) may result in complex non-linear dependencies due to the rapid conversion of salts into the parent drugs on an upper layer of the sample tablet during the experiment. ${ }^{8,10}$ The experimental IDR values for the CIP and NFX fumarates are listed in Table S3. $\uparrow$ The IDR of the salts in the $\mathrm{pH} 1.2$ buffer followed the same trend as the solubility of the compounds. Among the CIP-based salts, the highest IDR value is observed for $\left[\right.$ CIP + Fum $\left.+\mathbf{H}_{2} \mathrm{O}\right](1: 0.5: 1.5)$. Similarly, $[\mathrm{NFX}+$ Fum + $\mathrm{H}_{2} \mathrm{O}$ ] $(1: 0.5: 1)$ is found to be the most rapidly dissolving NFX salt. As expected, the metastable forms of fumarates are superior to their stable analogues in terms of their dissolution rates. The IDR value of the anhydrous [CIP + Fum] $(1: 1)$ salt is found to be 2.5 times greater than that of [CIP + Fum $\left.+\mathrm{H}_{2} \mathrm{O}\right](1: 1: 1)$. $\left[\mathrm{NFX}+\mathrm{Fum}+\mathrm{H}_{2} \mathrm{O}\right](1: 1: 1)$ demonstrates a modest $20 \%$ improvement in the IDR compared to the stable $\left[\mathrm{NFX}+\right.$ Fum $\left.+\mathrm{H}_{2} \mathrm{O}\right](1: 1: 2)$ form.

It should also be noted that the dissolution rate of $[\mathrm{NFX}+$ Fum $\left.+\mathbf{H}_{2} \mathbf{O}\right](1: 1: 1)$ exceeds that of $[\mathrm{CIP}+$ Fum] $(1: 1)$ by a factor of $c a$. 1.5. From kinetic considerations, the rate of solution phase transformation in the crystallization medium depends largely on the absolute and relative solubilities of the forms at that temperature. The higher the solubilities and the greater the difference in the solubilities of the two forms, the greater is the rate of transformation. ${ }^{52}$ It can be assumed, therefore, that the observed difference in the transformation rates of these salts during the powder dissolution (see 3.4.1, Fig. 10) is due to the differences in solubility and dissolution rate of the metastable forms.

\section{Conclusions}

In this work, a series of crystalline salts of ciprofloxacin and norfloxacin with fumaric acid have been obtained and characterised, each with a distinct drug/acid stoichiometry and hydration level. Each salt can be selectively obtained by mechanochemical treatment in the presence of water/organic mixtures of a particular composition. Despite having the same counterion, the ciprofloxacin and norfloxacin fumarates crystallise into distinct crystal structures, which consequently determine the differences in the relative stability and the corresponding physicochemical properties of the solid forms. According to the DSC and TG studies, the most hydrated salts 
showed poor thermal stability, releasing solvent below 100 ${ }^{\circ} \mathrm{C}$. In these forms, the water molecules are weakly bound to the host structure forming channel-like structures. The critical water activity measurements $\left(25^{\circ} \mathrm{C}\right)$ performed by slurry experiments have shown that anhydrous ciprofloxacin fumarate $([\mathbf{C I P}+\mathbf{F u m}](1: 1))$ is thermodynamically unstable at $a_{\mathrm{w}}$ values greater than 0.43 . In the case of norfloxacin salts, fumarate monohydrate $(1: 1: 1)\left(\left[\mathrm{NFX}+\right.\right.$ Fum $\left.\left.+\mathbf{H}_{2} \mathbf{O}\right](1: 1: 1)\right)$ has been found to be metastable at all $a_{\mathrm{w}}$ values, converting into either fumarate dihydrate $(1: 1: 2)$ at $a_{\mathrm{w}}>0.76$ or hemifumarate monohydrate $(1: 0.5: 1)$ at $a_{\mathrm{w}}<0.76$. Dissolution studies on $\left[\mathbf{N F X}+\mathbf{F u m}+\mathbf{H}_{2} \mathbf{O}\right](1: 1: 1)$ in buffer solutions with $\mathrm{pH} 1.2$ and $\mathrm{pH} 6.8$ indicate that transformation pathways of the salt are also pH-dependent, resulting in the formation of fumarate dihydrate $(1: 1: 2)$ in the acidic medium and hemifumarate monohydrate $(1: 0.5: 1)$ at neutral $\mathrm{pH}$. The largest solubility improvement relative to the parent drug $(\approx 33$ times) in $\mathrm{pH} 6.8$ medium was observed for ciprofloxacin hemifumarate sesquihydrate $\left(\left[\mathbf{C I P}+\right.\right.$ Fum $\left.\left.+\mathbf{H}_{2} \mathrm{O}\right](1: 0.5: 1.5)\right)$. In turn, the norfloxacin fumarates showed a moderate 3 -fold enhancement in solubility, which can be explained by an insignificant decrease in the lattice energy of the salts compared to the parent drug. In conclusion, the crystallization of norfloxacin and ciprofloxacin with fumaric acid can offer a diversity of solid forms. However, this study has shown that only a few of them have acceptable stability and solubility in order to be used in the context of formulation development.

\section{Conflicts of interest}

There are no conflicts to declare.

\section{Acknowledgements}

This work was supported by Fellowship of President of Russian Federation (SP-678.2016.4) and the Russian Science Foundation grant (No 14-13-00017. We thank "the Upper Volga Region Centre of Physicochemical Research" for technical assistance with the PXRD experiments.

\section{Notes and references}

1 M. I. Andersson and A. P. MacGowan, J. Antimicrob. Chemother., 2003, 51(suppl_1), 1.

2 F. van Bambeke, J. M. Michot, J. van Eldere and P. M. Tulkens, Clin. Microbiol. Infect., 2005, 11, 256.

3 S. A. Breda, A. F. Jimenez-Kairuz, R. H. Manzo and M. E. Olivera, Int. J. Pharm., 2009, 371, 106.

4 D. L. Ross and C. M. Riley, Int. J. Pharm., 1990, 63, 237.

5 H. Mesallati, N. A. Mugheirbi and L. Tajber, Cryst. Growth Des., 2016, 16, 6574.

6 H. Mesallati and L. Tajber, Pharm. Res., 2017, 11, 2425.

7 S. Basavoju, D. Boström and S. P. Velaga, Cryst. Growth Des., 2006, 6, 2699.

8 J. S. Reddy, S. V. Ganesh, R. Nagalapalli, R. Dandela, K. A. Solomon, K. A. Kumar, N. R. Goud and A. Nangia, J. Pharm. Sci., 2011, 100, 3160.
9 K. J. Paluch, T. McCabe, H. Muller-Bunz, O. I. Corrigan, A. M. Healy and L. Tajber, Mol. Pharmaceutics, 2013, 10, 3640.

10 A. O. Surov, A. N. Manin, A. P. Voronin, K. V. Drozd, A. A. Simagina, A. V. Churakov and G. L. Perlovich, Eur. J. Pharm. Sci., 2015, 77, 112.

11 A. O. Surov, A. V. Churakov and G. L. Perlovich, Cryst. Growth Des., 2016, 16, 6556.

12 G. Zhang, L. Zhang, D. Yang, N. Zhang, L. He, G. Du and Y. Lu, Acta Crystallogr., Sect. B: Struct. Sci., Cryst. Eng. Mater., 2016, 72, 20.

13 X. F. Huang, Z. H. Zhang, Q. Q. Zhang, L. Z. Wang, M. Y. He, Q. Chen, G.-Q. Song, L. Wei, F. Wang and M. Du, CrystEngComm, 2013, 15, 6090.

14 Y. Xu, L. Jiang and X. Mei, Acta Crystallogr., Sect. B: Struct. Sci., Cryst. Eng. Mater., 2014, 70, 750.

15 P. P. Bag, S. Ghosh, H. Khan, R. Devarapalli and C. M. Reddy, CrystEngComm, 2014, 16, 7393.

16 R. Chadha, P. Singh, S. Khullar and S. K. Mandal, Cryst. Growth Des., 2016, 16, 4960.

17 C. B. Romañuk, R. H. Manzo, Y. G. Linck, A. K. Chattah, G. A. Monti and M. E. Olivera, J. Pharm. Sci., 2009, 98, 3788.

18 S. P. Velaga, S. Basavoju and D. Boström, J. Mol. Struct., 2008, 889, 150.

19 C. B. Romañuk, Y. G. Linck, A. K. Chattah, G. A. Monti, S. L. Cuffini, M. T. Garland, R. Baggio, R. H. Manzo and M. E. Olivera, Int. J. Pharm., 2010, 391, 197.

20 S. Basavoju, D. Boström and S. P. Velaga, Mol. Cryst. Liq. Cryst., 2012, 562, 254.

21 S. P. Gopi, S. Ganguly and G. R. Desiraju, Mol. Pharmaceutics, 2016, 13(10), 3590.

22 U.S. Food and Drug Administration Orange Book, http:// www.accessdata.fda.gov/scripts/cder/ob/.

23 M. Pudipeddi, A. T. M. Serajuddin, D. J. W. Grant and P. H. Stahl, in Handbook of pharmaceutical salts, properties, selection and use, ed. P. H. Stahl and C. G. Wermuth, WileyVCH, Weinheim, Germany, 2002, p. 19.

24 G. S. Paulekuhn, J. B. Dressman and C. Saal, J. Med. Chem., 2007, 50, 6665.

25 A. K. Bansal, L. Kumar and A. Amin, Pharm. Technol., 2008, 3, 32.

26 H. D. Clarke, K. K. Arora, H. Bass, P. Kavuru, T. T. Ong, T. Pujari, L. Wojtas and M. J. Zaworotko, Cryst. Growth Des., 2010, 10, 2152.

27 R. A. Storey and I. Ymen, Solid state characterization of pharmaceuticals, Wiley, Chichester, 2012.

28 G. M. Sheldrick, SADABS, Program for scaling and correction of area detector data, University of Göttingen, Germany, 1997.

29 G. M. Sheldrick, Acta Crystallogr., Sect. A: Found. Crystallogr., 2007, 64, 112.

30 O. V. Dolomanov, L. J. Bourhis, R. J. Gildea, J. A. K. Howard and H. Puschmann, J. Appl. Crystallogr., 2009, 42, 339.

31 H. Zhu, C. Yuen and D. Grant, Int. J. Pharm., 1996, 135, 151.

32 M. C. Etter, Acc. Chem. Res., 1990, 23, 120.

33 J. Bernstein, R. E. Davis, L. Shimoni and N.-L. Chang, Angew. Chem., Int. Ed. Engl., 1995, 34, 1555. 
34 M. R. Caira, G. Bettinetti and M. Sorrenti, J. Pharm. Sci., 2002, 91, 467.

35 F. Tian, H. Qu, A. Zimmermann, T. Munk, A. C. Jørgensen and J. Rantanen, J. Pharm. Pharmacol., 2010, 62, 1534.

36 D. E. Braun, R. M. Bhardwaj, J. B. Arlin, A. J. Florence, V. Kahlenberg, U. J. Griesser, D. A. Tocher and S. L. Price, Cryst. Growth Des., 2013, 13, 4071-4083.

37 D. E. Braun and U. J. Griesser, Cryst. Growth Des., 2016, 16, 6111.

38 D. J. W. Grant and T. Higuchi, Solubility Behavior of Organic Compounds, John Willey and Sons, New York, 1990.

39 E. Tieger, V. Kiss, G. Pokol and Z. Finta, CrystEngComm, 2017, 19, 1912.

40 X. Wang, L. Dang, S. Black, X. Zhang and H. Wei, Ind. Eng. Chem. Res., 2012, 51, 2789.

41 H. Peng, H. Li, C. Wang, D. Zhang, B. Pan and B. Xing, Chemosphere, 2014, 103, 322.

42 W. Yang, X. Jiang, Y. Hu, Y. Shi, H. Sun and Y. Li, J. Solution Chem., 2013, 42, 1591.
43 S. Z. Mikhail and W. R. Kimel, J. Chem. Eng. Data, 1961, 6, 533.

44 A. Jayasankar, L. S. Reddy, S. J. Bethune and N. RodríguezHornedo, Cryst. Growth Des., 2009, 9, 889.

45 Z. Li and A. J. Matzger, Mol. Pharmaceutics, 2016, 14, 990.

46 X. Yu, G. L. Zipp and G. W. Ray Davidson III, Pharm. Res., 1994, 11, 522.

47 K. A. Roa Engel, J. H. ter Horst, M. Pieterse, L. A. M. van der Wielen and A. J. J. Straathof, Ind. Eng. Chem. Res., 2013, 52, 9454.

48 N. J. Babu and A. Nangia, Cryst. Growth Des., 2011, 11, 2662.

49 A. I. Caço, F. Varanda, M. J. Pratas de Melo, A. M. Dias, R. Dohrn and I. M. Marrucho, Ind. Eng. Chem. Res., 2008, 47, 8083.

50 C. Florindo, A. Costa, C. Matos, S. L. Nunes, A. N. Matias, C. M. Duarte, L. P. Rebelo, L. C. Branco and I. M. Marrucho, Int. J. Pharm., 2014, 469, 179.

51 S. H. Yalkowsky, Y. He and P. Jain, Handbook of aqueous solubility data, CRC press, 2010.

52 H. Zhu and D. J. Grant, Int. J. Pharm., 1996, 139, 33. 